\title{
The impact of COVID-19 lockdown on child and adolescent mental health: systematic review
}

\author{
Urvashi Panchal ${ }^{8} \cdot$ Gonzalo Salazar de Pablo $^{1,2,3,8}\left(\mathbb{D} \cdot\right.$ Macarena Franco $^{4} \cdot$ Carmen Moreno $^{3} \cdot$ Mara Parellada $^{3}$. \\ Celso Arango $^{3} \cdot$ Paolo Fusar-Poli ${ }^{2,5,6,7}$
}

Received: 16 March 2021 / Accepted: 31 July 2021

(c) The Author(s) 2021

\begin{abstract}
COVID-19 was declared a pandemic in March 2020, resulting in many countries worldwide calling for lockdowns. This study aimed to review the existing literature on the effects of the lockdown measures established as a response to the COVID-19 pandemic on the mental health of children and adolescents. Embase, Ovid, Global Health, PsycINFO, Web of Science, and pre-print databases were searched in this PRISMA-compliant systematic review (PROSPERO: CRD42021225604). We included individual studies reporting on a wide range of mental health outcomes, including risk and protective factors, conducted in children and adolescents (aged $\leq 19$ years), exposed to COVID-19 lockdown. Data extraction and quality appraisal were conducted by independent researchers, and results were synthesised by core themes. 61 articles with 54,999 children and adolescents were included (mean age $=11.3$ years, $49.7 \%$ female). Anxiety symptoms and depression symptoms were common in the included studies and ranged $1.8-49.5 \%$ and $2.2-63.8 \%$, respectively. Irritability (range $=16.7-73.2 \%$ ) and anger (range $=30.0-51.3 \%$ ), were also frequently reported by children and adolescents. Special needs and the presence of mental disorders before the lockdown, alongside excessive media exposure, were significant risk factors for anxiety. Parent-child communication was protective for anxiety and depression. The COVID-19 lockdown has resulted in psychological distress and highlighted vulnerable groups such as those with previous or current mental health difficulties. Supporting the mental health needs of children and adolescents at risk is key. Clinical guidelines to alleviate the negative effects of COVID-19 lockdown and public health strategies to support this population need to be developed.
\end{abstract}

Keywords COVID-19 $\cdot$ Coronavirus $\cdot$ Lockdown $\cdot$ Children $\cdot$ Adolescents $\cdot$ Mental health $\cdot$ Systematic review

Gonzalo Salazar de Pablo

gonzalo.salazar_de_pablo@kcl.ac.uk

1 Child and Adolescent Mental Health Services, South London and the Maudsley NHS Foundation Trust, London, UK

2 Early Psychosis: Interventions and Clinical-Detection (EPIC) Lab, Department of Psychosis Studies, Institute of Psychiatry, Psychology \& Neuroscience, King's College London, London, UK

3 Institute of Psychiatry and Mental Health. Department of Child and Adolescent Psychiatry, Hospital General Universitario Gregorio Marañón, School of Medicine, Universidad Complutense, Instituto de Investigación Sanitaria Gregorio Marañón (IiSGM), CIBERSAM, Madrid, Spain
4 Department of Psychiatry, Hospital Dr Rodríguez Lafora, Universidad Autónoma Madrid, Madrid, Spain

5 Department of Brain and Behavioral Sciences, University of Pavia, Pavia, Italy

6 OASIS Service, South London and Maudsley National Health Service Foundation Trust, London, UK

7 National Institute for Health Research, Maudsley Biomedical Research Centre, South London and Maudsley NHS Foundation Trust, London, UK

8 Department of Child and Adolescent Psychiatry, Institute of Psychiatry, Psychology and Neuroscience, PO63, 16 De Crespigny Park, London SE5 8AF, UK 


\section{Introduction}

In January 2020, WHO first identified the novel coronavirus (COVID-19), later declaring the spread of COVID-19 as a global pandemic in March 2020 [29]. Subsequently, many countries imposed national lockdowns, closing schools and workplaces, leaving people to learn virtually, enforcing social distancing measures, and implementing restrictive measures that prevented individuals from going to public places or from meeting people from other households [45].

Quarantines and lockdowns are states of isolation that are psychologically distressing and unpleasant for anyone who experiences them $[14,50]$. Young people, who are at higher risk of developing mental health problems than adults [32], may be particularly vulnerable to the adverse effects of isolation, including school closures, due to the disruption lockdown causes on their physical activity and social interaction [101].

Previous systematic reviews and meta-analyses have looked at the impact of COVID-19 on the mental health of the general population [108] and healthcare workers [31]. One previous systematic review looked at the psychological burden of quarantine associated with exposure to contagious diseases on children and adolescents but included only three articles on COVID-19 [49]. To our knowledge, this is the first comprehensive systematic review focusing exclusively on the impact of the COVID-19 pandemic response lockdown on child and adolescent mental health.

This systematic review aims to summarise the literature exploring the effects of COVID-19 lockdown on a wide range of mental health outcomes in children and adolescents. We further explore the risk factors and protective factors for developing mental health outcomes in the context of COVID-19 lockdown.

\section{Methods}

The format of the methods and results was based on the Preferred Reporting Items for Systematic Reviews and MetaAnalyses (PRISMA) guidelines [70] (eTable 1) (study protocol registered on PROSPERO: CRD42021225604).

\section{Search strategy and selection criteria}

A systematic search was conducted by two independent researchers (UP, MF) on Embase, Ovid MEDLINE (R), Global Health, Web of Science, and APA PsycINFO from inception until the 1st of April 2021. The search terms used can be found in eMethods 1 . As this is an emerging topic, we looked at medRxiv, psyArXiv, and bioRxiv pre-print databases to identify further relevant studies. A manual search of the references of the included studies and reviews related to this topic was conducted using Google Scholar. Articles identified were screened as abstracts. After excluding those that did not meet our inclusion criteria, the full texts of the remaining articles were assessed for eligibility and decisions were made regarding their final inclusion in the review.

The inclusion criteria were as follows: (1) individual studies with original data, including grey literature, (2) conducted in children and adolescents aged $\leq 19$ years, (3) exposed to COVID-19 lockdown, as operationalised in each study (see eTable 2), (4) evaluating mental health outcomes (see eTable 3 for the full list of outcomes), (5) in English. The exclusion criteria were as follows: (1) conference proceeding, abstracts, case reports or reviews, (2) studies including adults $>19$ years, (3) studies in which children and adolescents were not exposed to COVID-19 lockdown, (4) studies focusing on physical health outcomes only.

\section{Data extraction}

Independent researchers (UP, MF) carried out data extraction. Any discrepancies arising were resolved through consensus, consulting another researcher (GSP) if an agreement was not attained. The variables extracted included: lead author/year, country, study design (cross-sectional, cohort, qualitative, mixed methods), sample size, sex (\% females), age (mean $\pm \mathrm{SD}$, range), exposure data (lockdown definition, length of lockdown), instruments, outcomes (see eTable 3), report (parent, children), quality appraisal (see below) and key findings.

\section{Strategy for data synthesis}

The results of the systematic review were summarised in tables and narratively synthesised. Results were stratified by poor mental health outcomes and risk factors, followed by good mental health outcomes and protective factors.

\section{Quality appraisal}

For study appraisal, this review used the Newcastle-Ottawa Scale (NOS) adapted for cross-sectional studies [69], which has been attached as a supplementary file (eMethods 2). This scale has three domains: selection, comparability, and outcome. The domain of selection has four categories assessing the representativeness of the sample, the sample size, the number of non-respondents, and the ascertainment of the exposure, with a maximum of five stars to be awarded. The domain of comparability has one category assessing if confounding factors are controlled for, with the maximum award of two stars. The 
final domain of outcome has two categories assessing the outcome and the appropriate usage of statistical tests, with the maximum award of three stars. All categories can score one star, apart from the ascertainment of the exposure and assessment of the outcome, both of which can score two stars. A total of 10 stars can be awarded if a study meets all the criteria specified.
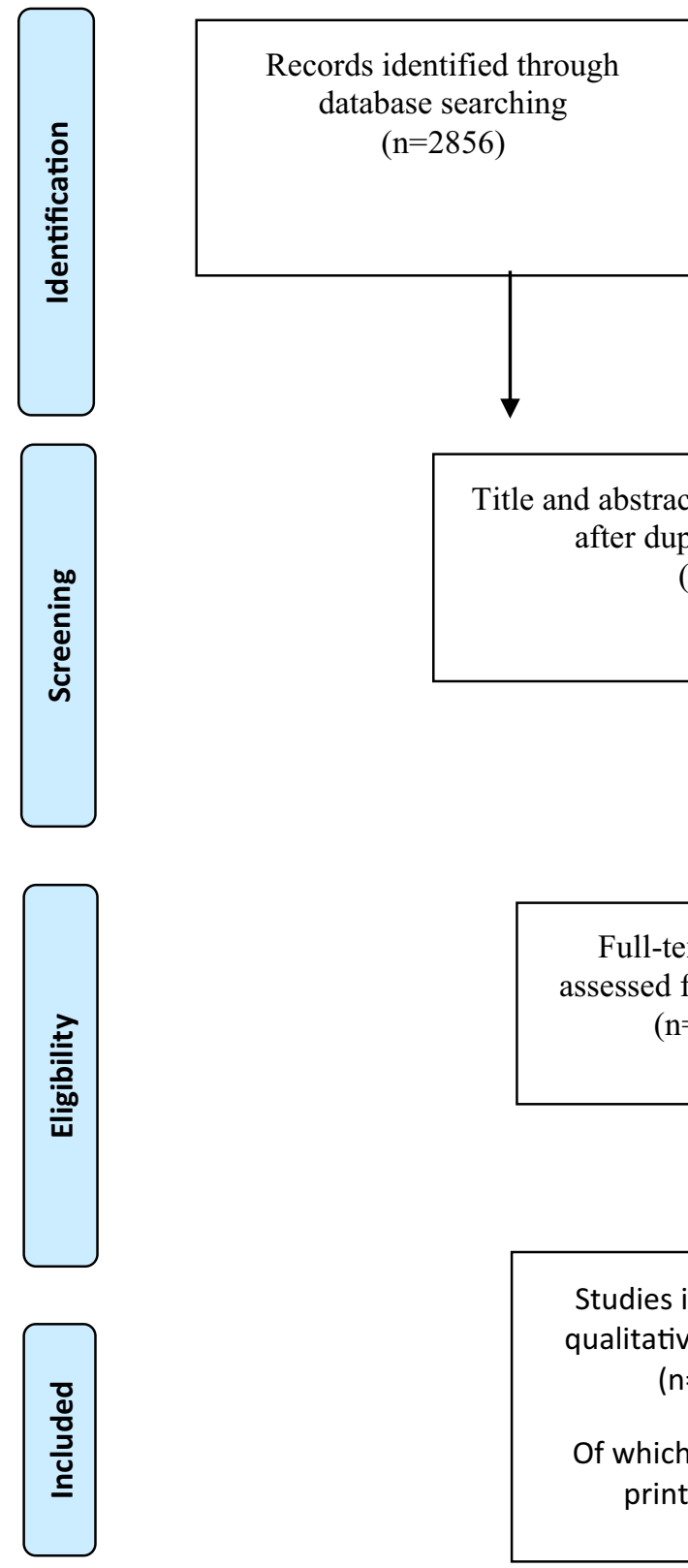

\section{Results}

\section{Search results}

A systematic electronic search identified a total of 2856 publications and 41 additional articles were found via backward searching of key papers. Of those, 324 publications underwent full-text screening. A total of 263 publications were excluded at the full-text screening stage and 61 articles finally met the criteria for inclusion, 3 of which were

Additional records identified through other sources

$$
(\mathrm{n}=38)
$$

Additional records identified through pre-prints $(\mathrm{n}=3)$

Title and abstract screened for eligibility after duplicated removed $(\mathrm{n}=2758)$

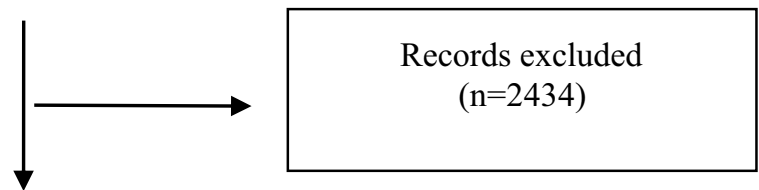

Full-text articles assessed for eligibility $(n=324)$

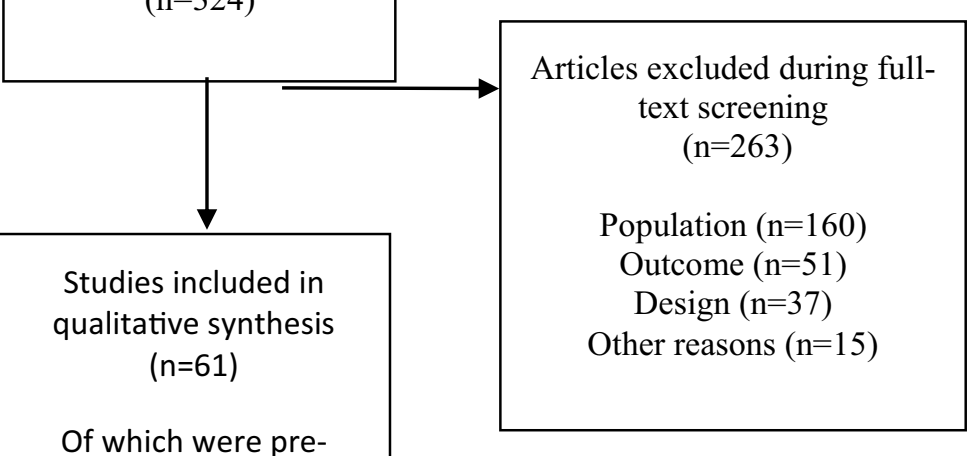

Fig. 1 PRISMA flowchart 
identified in the pre-print databases. Results of the search follow in the PRISMA 2009 flow diagram (Fig. 1).

\section{Study characteristics}

The sample sizes within the included studies ranged 15-7,772 participants, $(n=54,999)$. The mean age of participants was 11.3 years (range: $1-19$ years). $49.7 \%$ of participants were female. Most studies were cross-sectional studies $(n=45,73.8 \%)$ while the rest were longitudinal studies $(n=16,26.2 \%)$. Included studies took place across five continents including Europe $(n=35,57.4 \%)$, Asia $(n=22$, $36.1 \%)$, Australia $(n=1,1.6 \%)$, North America $(n=1$, $1.6 \%)$, South America $(n=1,1.6 \%)$, and across more than one continent $(n=1,1.6 \%)$. Most studies involved only parent self-reports $(n=21,18,655)$ or solely child self-reports $(n=20,25,327)$, while other studies involved both parent and child self-reports $(n=10,7,931)$. A proportion of studies $(n=10,2,321)$ utilised interviews, of which some were parent interviews $(n=2,535)$, some were child interviews $(\mathrm{n}=5,2,629)$, and some interviewed both parents and children $(n=3,261)$. Duration of lockdown was $52.3 \pm 21.3$ days in the included studies (range $30[1,4,12,17,25,27,34$, $39,41,57,82]-100$ days [80, 100]). The characteristics of the included studies and their findings are summarised in Table 1.

\section{Poor mental health outcomes and risk factors}

Most commonly evaluated outcomes in the included studies (see eTables 3-4) were anxiety $(\mathrm{n}=35,57.4 \%)$ and depression $(n=24,39.3 \%)$. Symptoms of anxiety exacerbation were reported during or related/associated to lockdown in $57.4 \%$ of studies $[1,3,5,6,11,12,16,18,20,27$, $39,41,47,48,51,53,56,62,72,75,79,80,82,86-90$, $94,103,107,109,110,112]$. The prevalence of symptoms of anxiety ranged from 1.8\% [110] to $49.5 \%$ [41] between studies. $59.6 \%$ of young people reported increased ruminations [11]. 13.4\% of children were found to be experiencing severe anxiety [109]. Meanwhile, 3.2\% of children and adolescents met DSM-5 criteria for PTSD [110]. Risk factors to anxiety included lack of routine $(p<0.001)$ [6], female sex $(p<0.001)$ [20] $(p=0.041)$ [62], adolescence $(p=0.005)$ [44], excessive COVID-19 information $(p<0.05)$ defined by repeated exposure to COVID-19 related information [110], media exposure $(\mathrm{OR}=2.4)$ [51], and being previously referred for psychiatric treatment $(\mathrm{OR}=4.4)$ [51] (Fig. 2). An increased social media usage was associated with a higher risk of developing anxiety symptoms or and depression symptoms ( $\mathrm{OR}=1.83, p=0.001)$ [89]. Children with Autism Spectrum Disorders (ASD) showed more anxiety than children without ASD during the lockdown [6].
Symptoms of depression were the second most commonly reported outcomes $(n=24,39.3 \%)[2,7,12,18,20$, $25,41,47,48,56,62,63,72,80,83,86,89,94,106,107$, 109-112]. The prevalence of symptoms of depression ranged between 2.2\% [110] and 63.8\% [41] amongst studies. 7\% of young people reported anhedonia [78]. The prevalence of children and adolescents with severe depression increased from 10 to $27 \%$ [41]. The prevalence of non-suicidal selfinjury $(\mathrm{OR}=1.35, p<0.001)$, suicide ideation $(\mathrm{OR}=1.32$, $p=0.008)$, suicide planning $(\mathrm{OR}=1.71, p<0.001)$, and suicide attempts $(\mathrm{OR}=1.74, p<0.001)$ increased from November 2019 to May 2020 after lockdown [111]. Common risk factors for depression included female sex $(p<0.001)$ [18, $25,62]$, being an adolescent $(p<0.01)[18,83]$, a high amount of COVID-19 cases in the area $(\mathrm{OR}=2.3, p<0.001)$ $[83,107]$, and being exposed to a relative doing first-line job responsibilities related to COVID-19 $(p<0.05)$ [20]. Anger and irritability were common outcomes within children and adolescents ranging from $30.0 \%$ [78] to 51.3\% [86] and from $16.7 \%$ [6] to $73.2 \%$ [86], respectively.

Symptoms of ADHD were frequently reported $(n=12$, 19.7\%) [17, 25, 34, 42, 59, 64, 74, 75, 85, 88, 91, 100]. Particularly, difficulties concentrating ranged from $55.9 \%$ [25] to $76.6 \%(p<0.001)$ [75] in children and adolescents exposed to lockdown. Hyperactivity/inattention difficulties increased during lockdown $(p<0.001)$ [34, 42]. Exacerbation in symptoms of ADHD were related to increases in activity levels $(50.1 \%)$, irritability (45.8\%), disruptive behaviour (47.7\%) [88], and conduct problems [74]. Risk factors for symptoms of ADHD worsening included sleep problems [17], being male $(p<0.001)$ [64], being a child compared to being an adolescent $(p<0.05)$ [85, 100], and parental stress $(p<0.001)$ [91].

Sleep disturbances were reported in a portion of the included studies $(n=11,18.0 \%) .20 \%$ of children [79] and $55.6 \%$ of adolescents reported difficulty sleeping [25]. The proportion of children with sleep disorders increased from 40 to $62 \%$ during lockdown [54]. Young people showed difficulties initiating and maintaining sleep, the frequency of parasomnia increased [54]. Most studies reporting on sleep disturbances found that young people slept for longer during lockdown $(p<0.001)[39,54]$. Children went to bed $\sim 53 \mathrm{~min}$ later $(p<0.0001)$ and woke up 66 min later $(p<0.0001)$ than before the lockdown [34].

Longitudinal research findings showed a rise in children's depressive symptoms [12] and anxiety symptoms compared to before the lockdown $(p<0.001)[19,62]$. Their risk increased when spending more time on COVID-19 media reports $(p<0.05)$ [110]. Furthermore, $41 \%$ of children and adolescents experienced a reactivation in eating disorder symptoms post lockdown, with a more pronounced reactivation of disordered eating seen in adolescents [44]. 


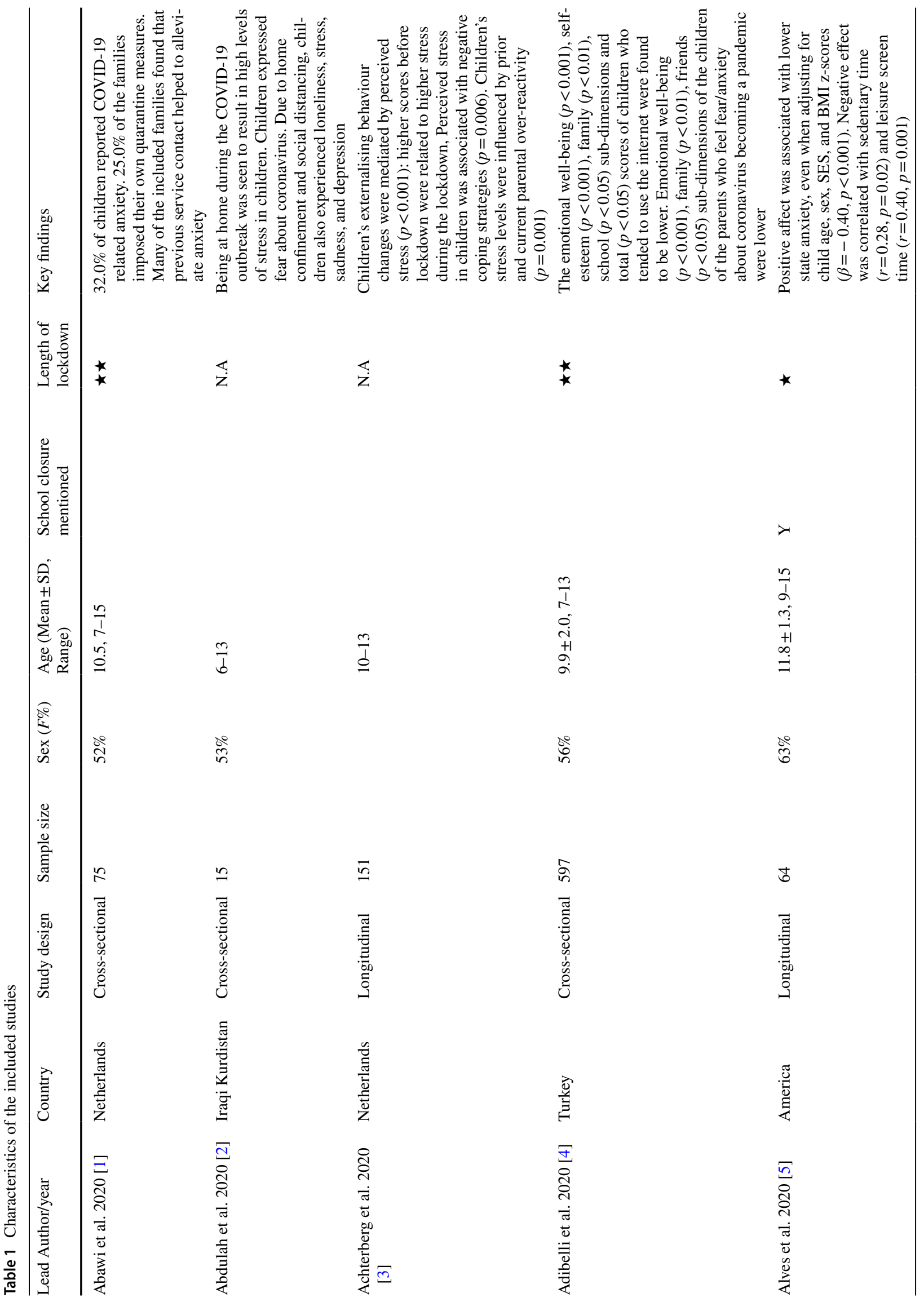




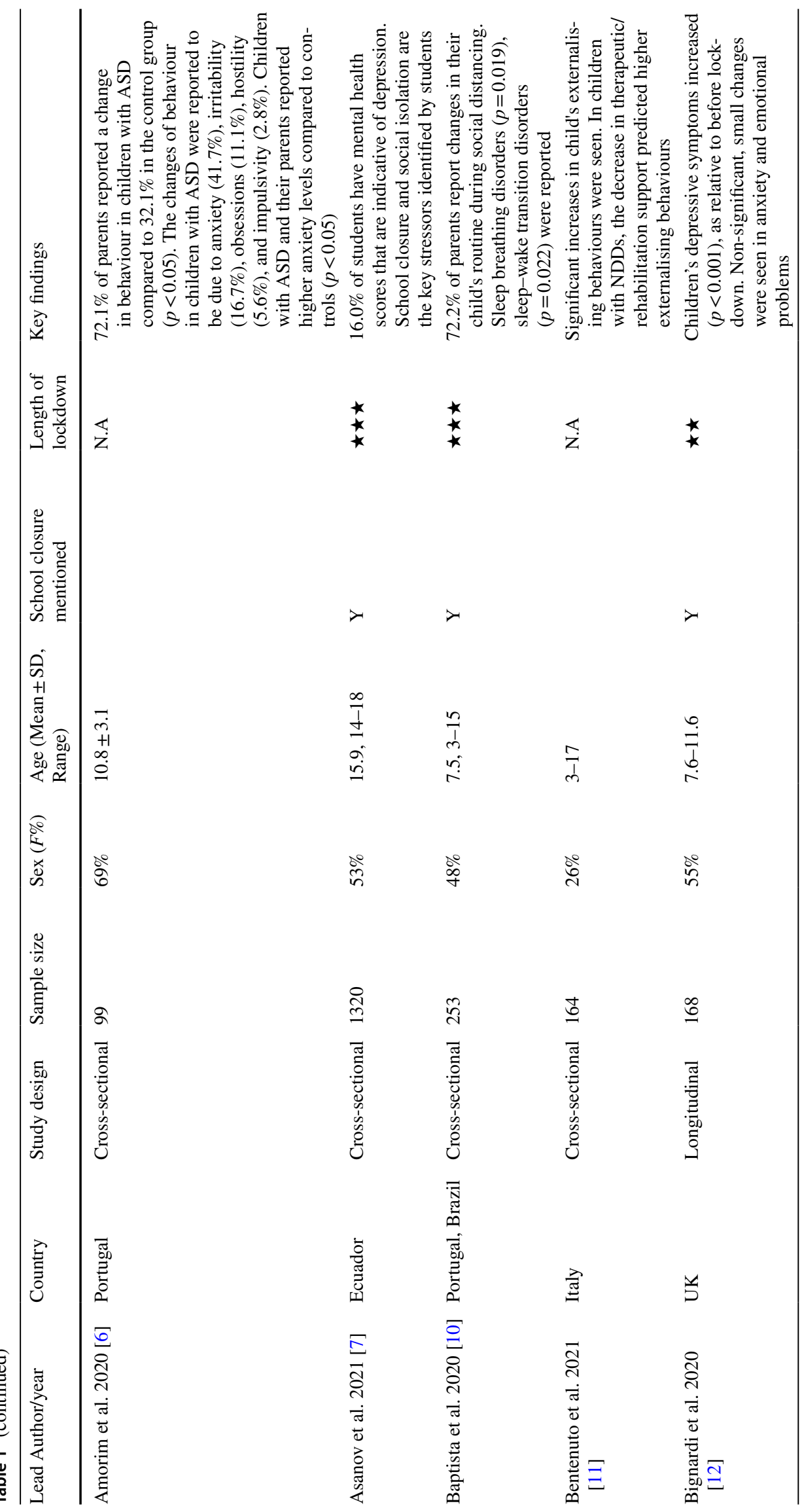




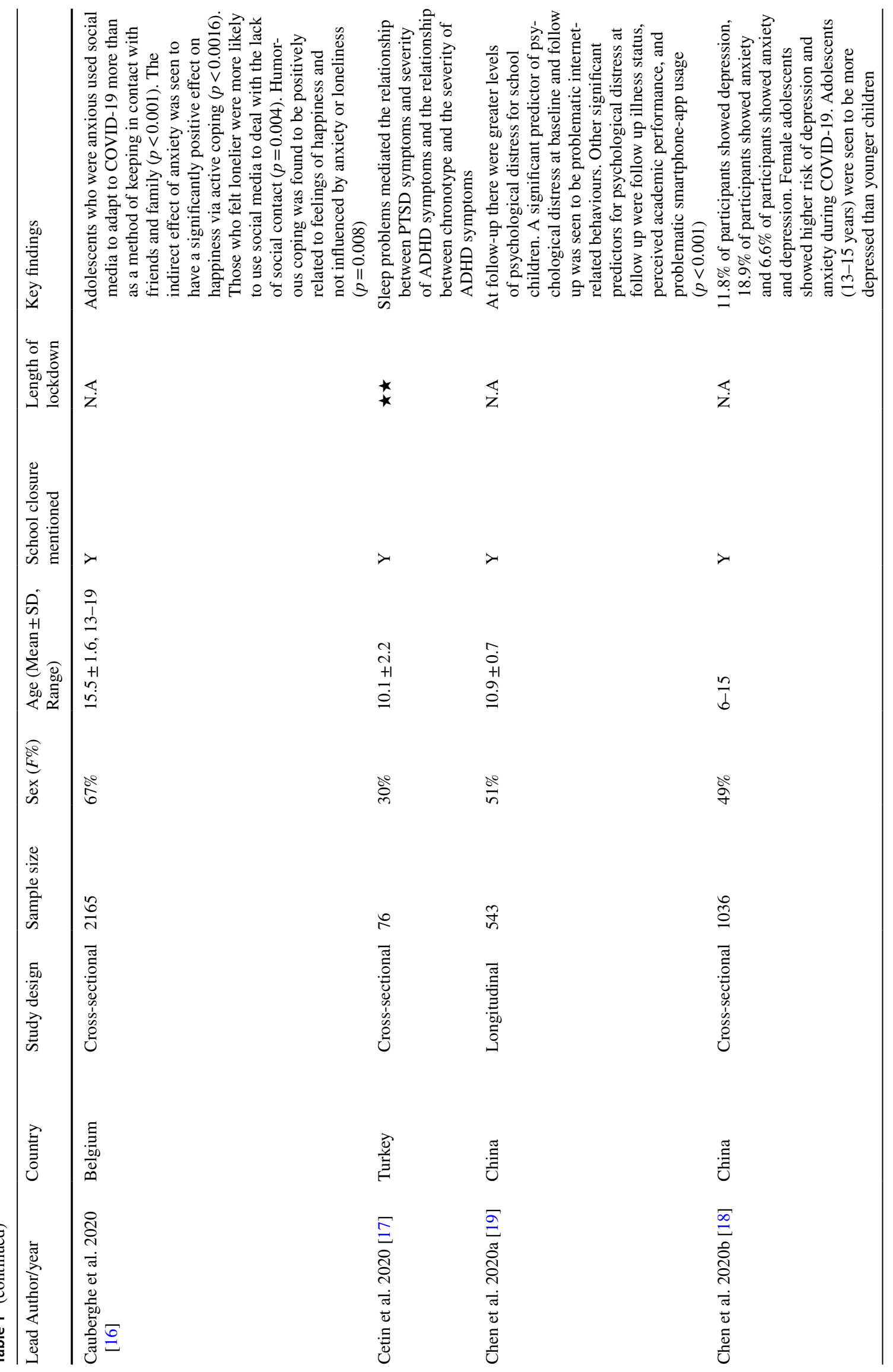




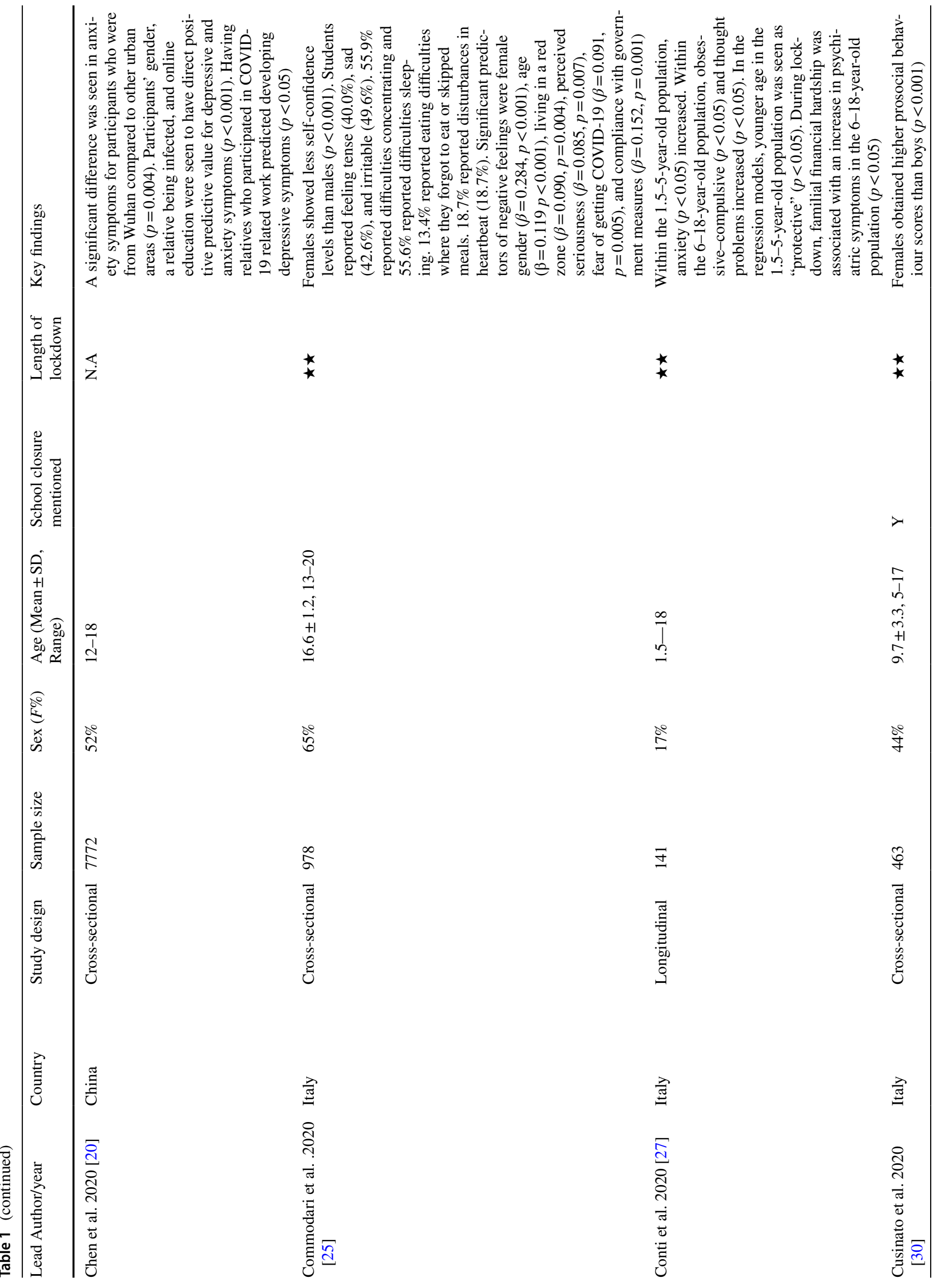




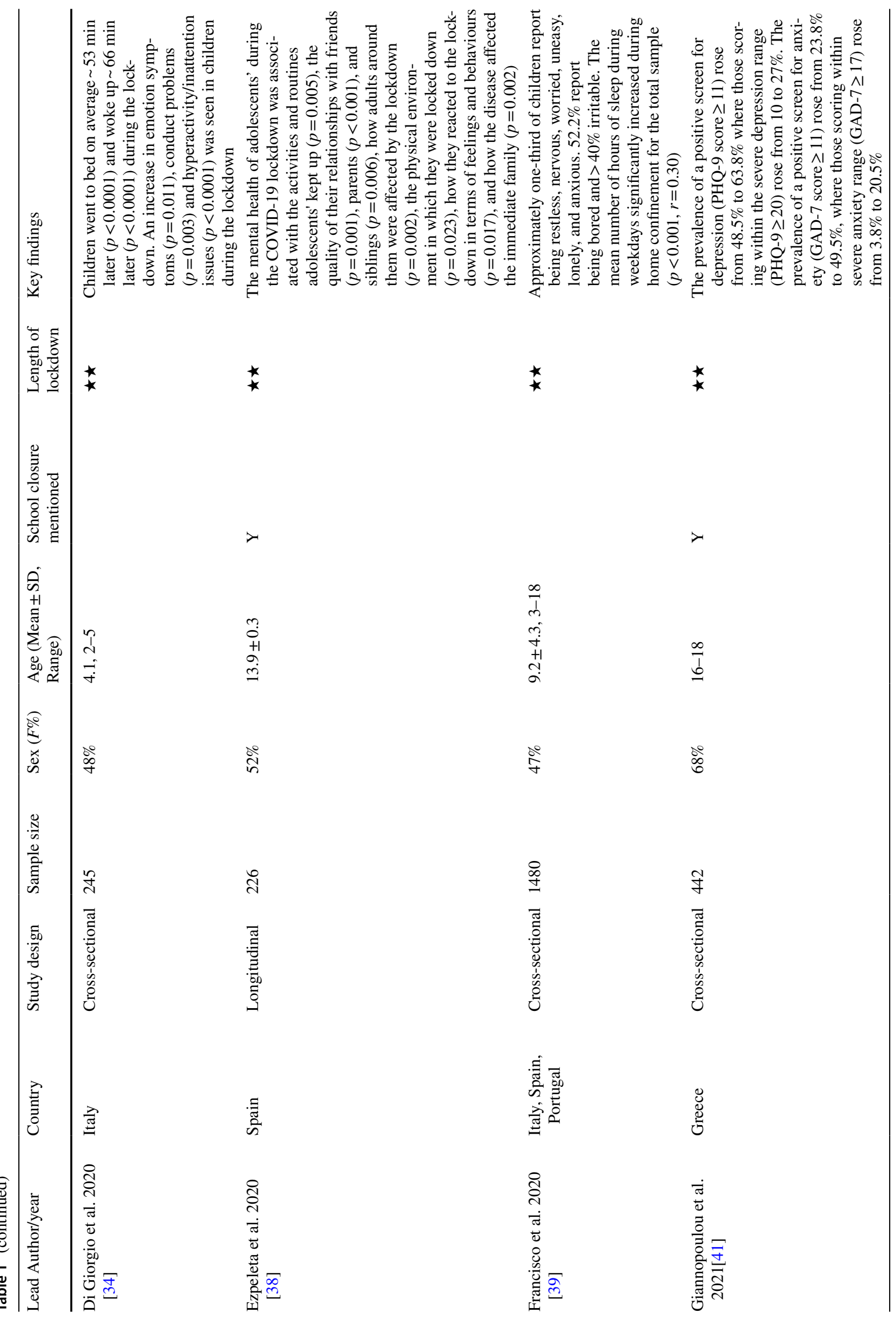




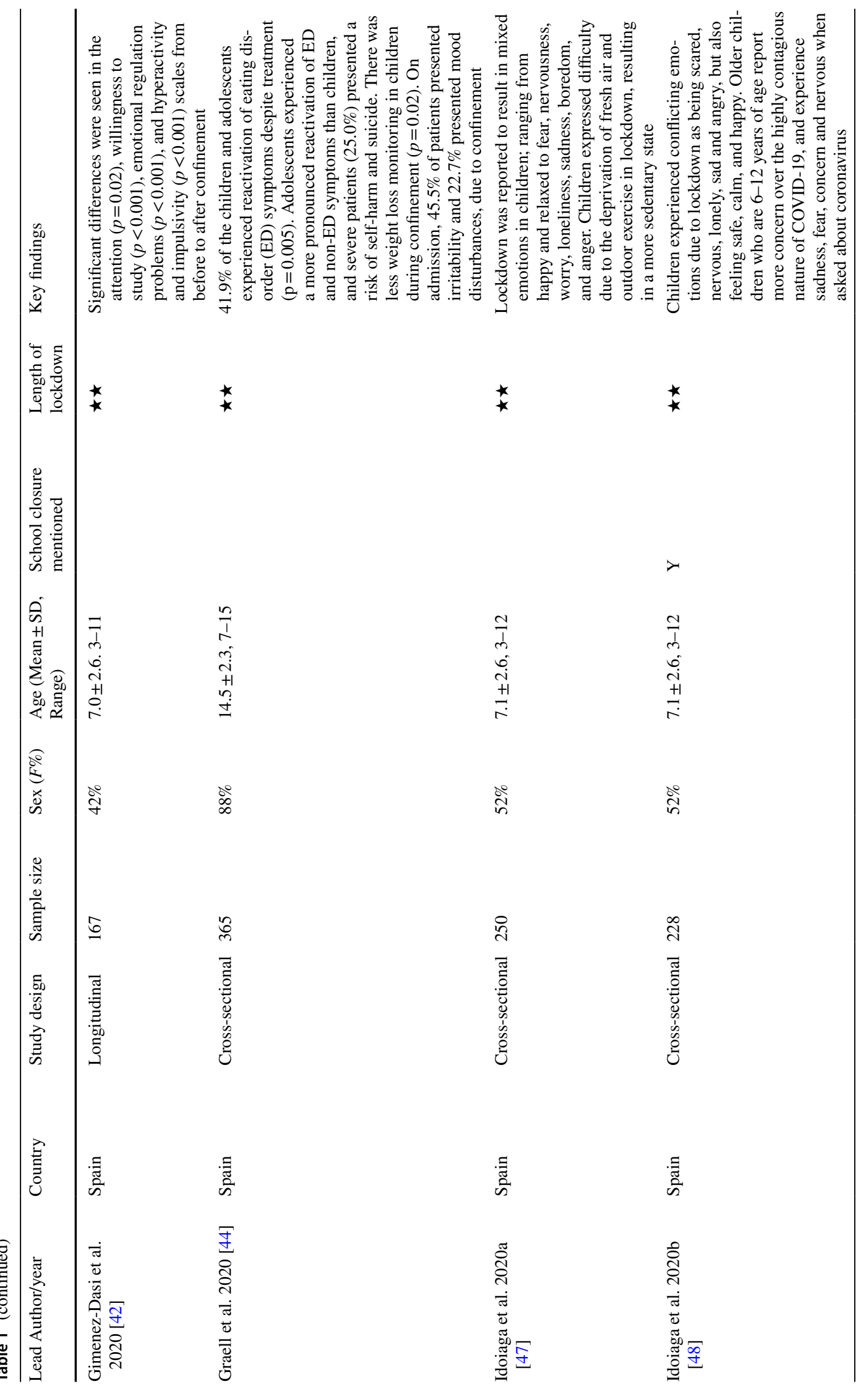




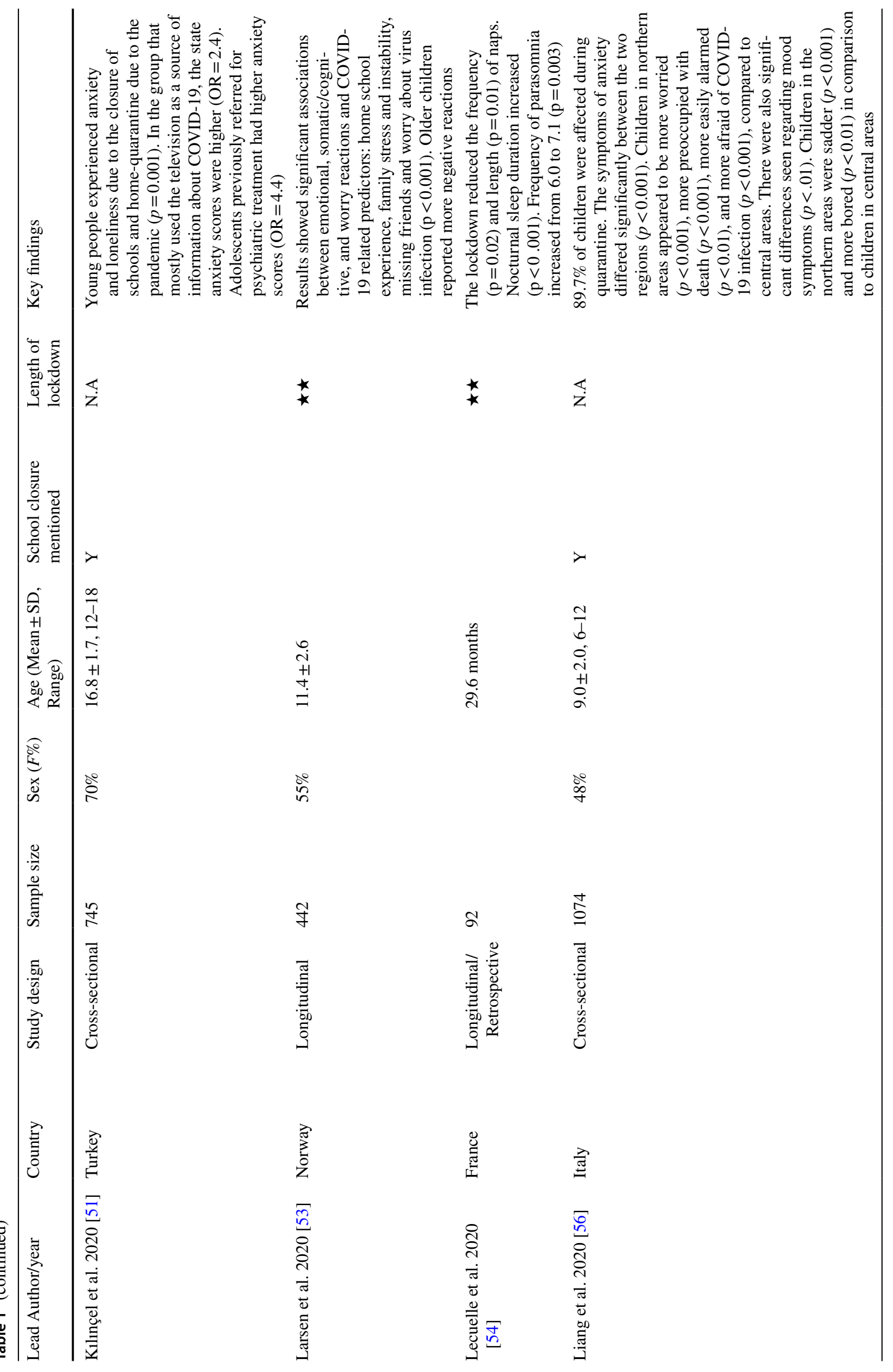




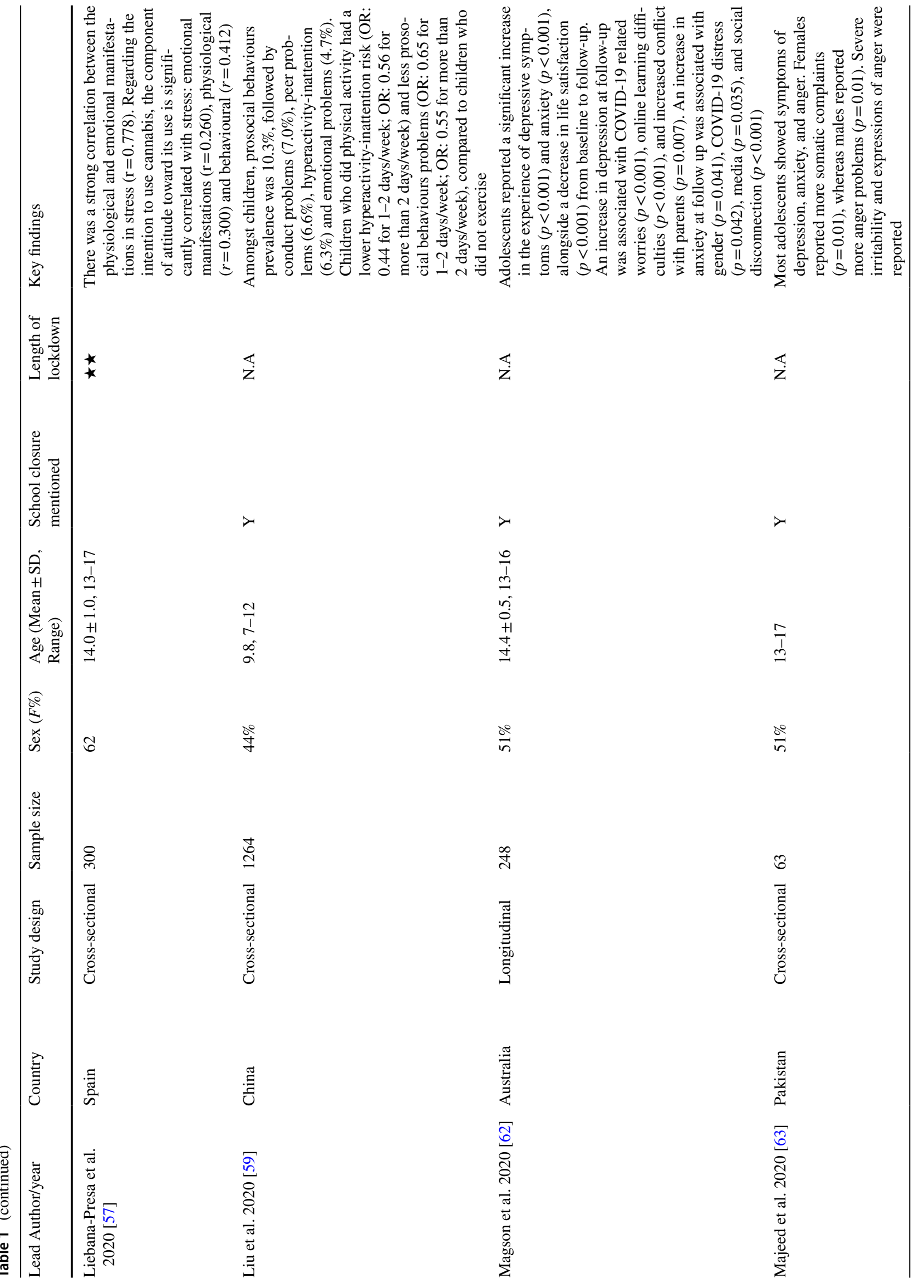




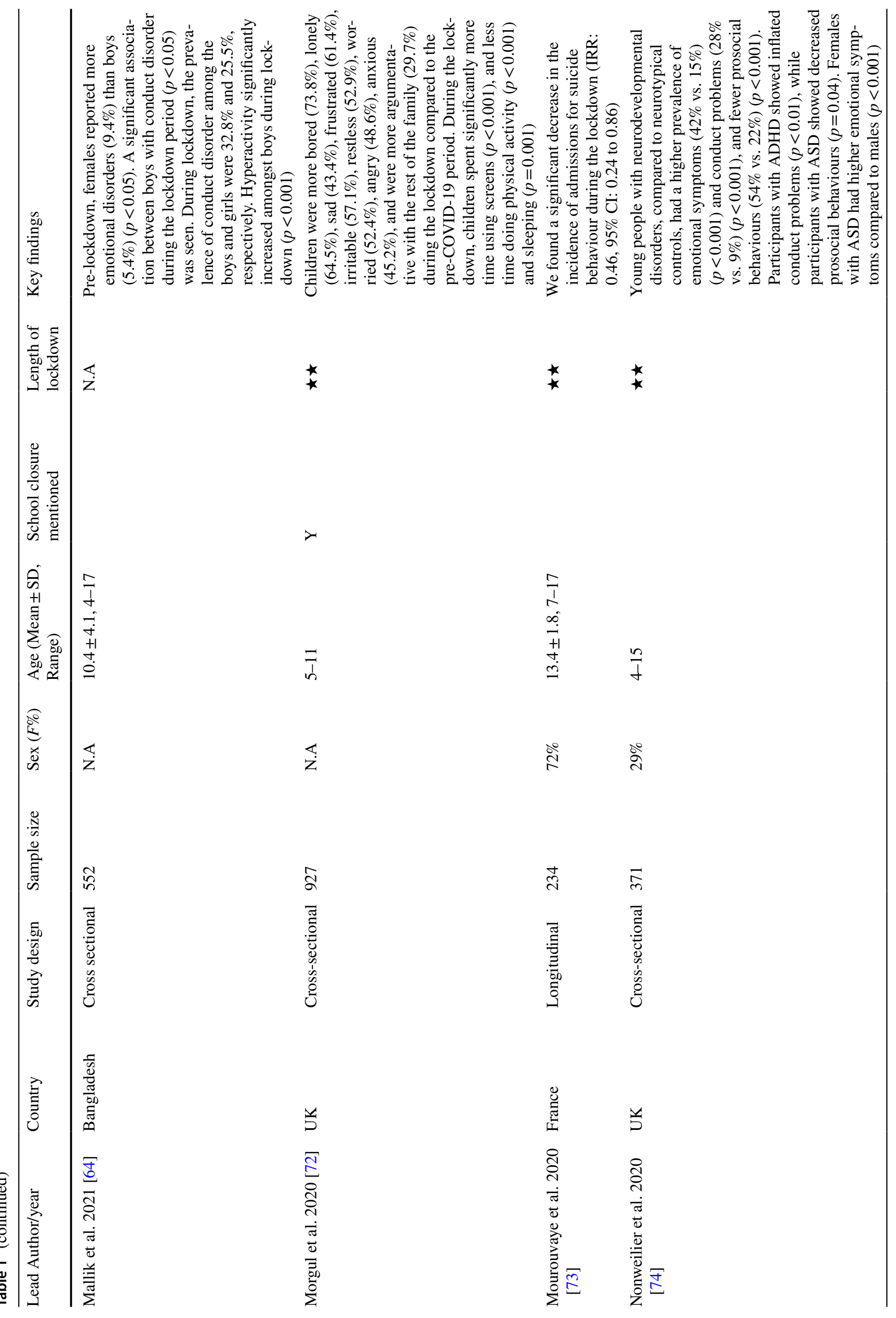




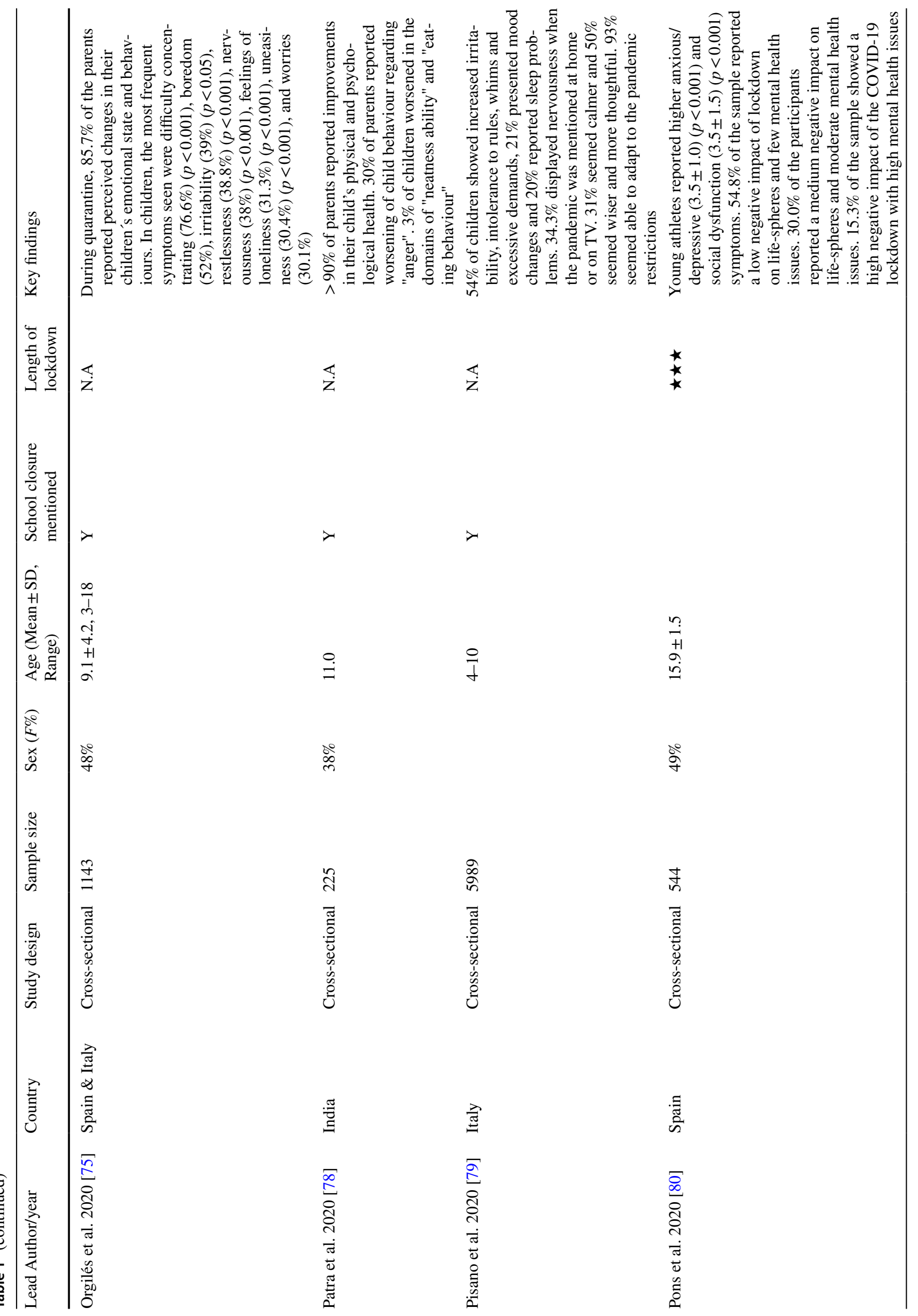




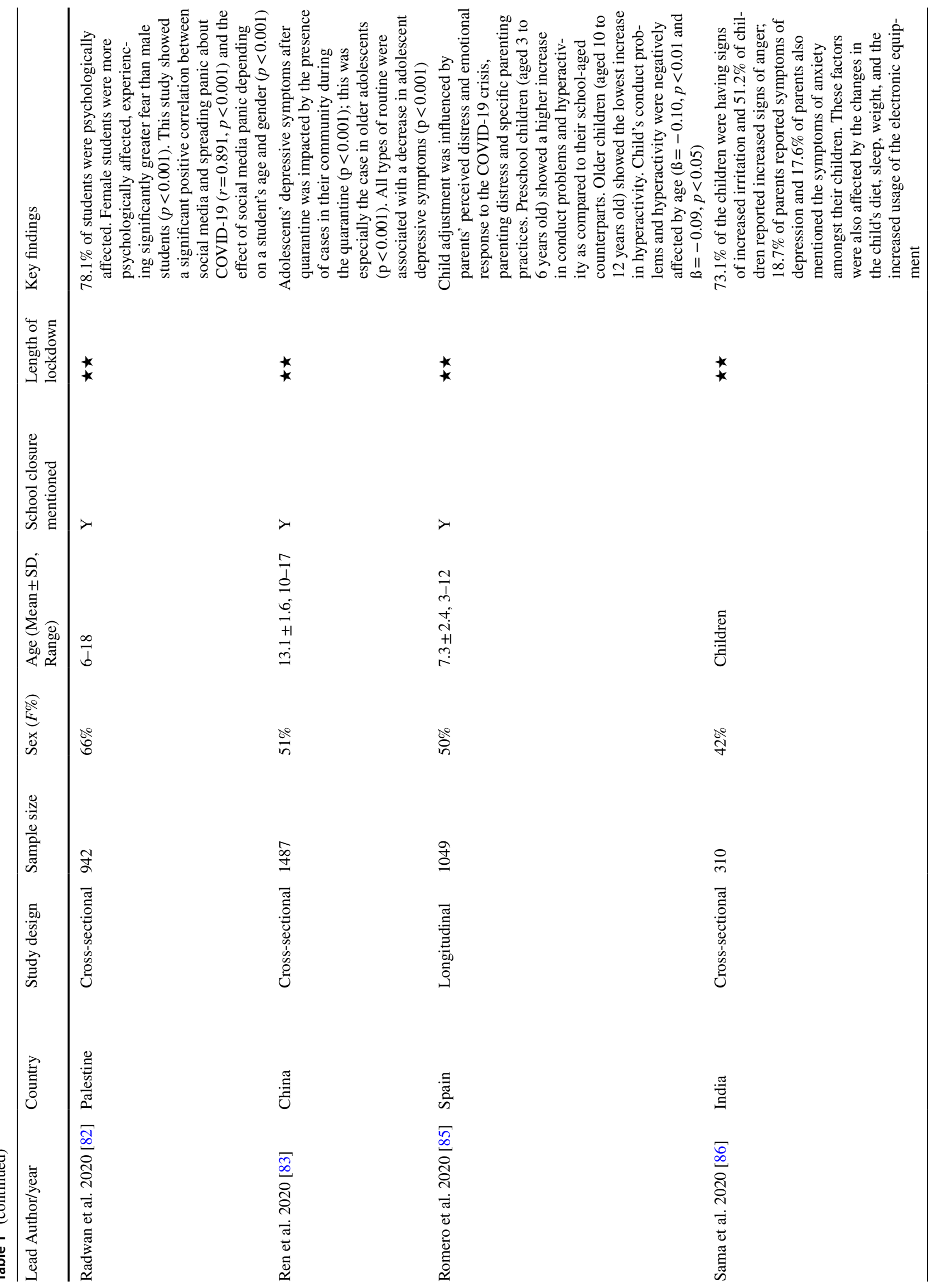




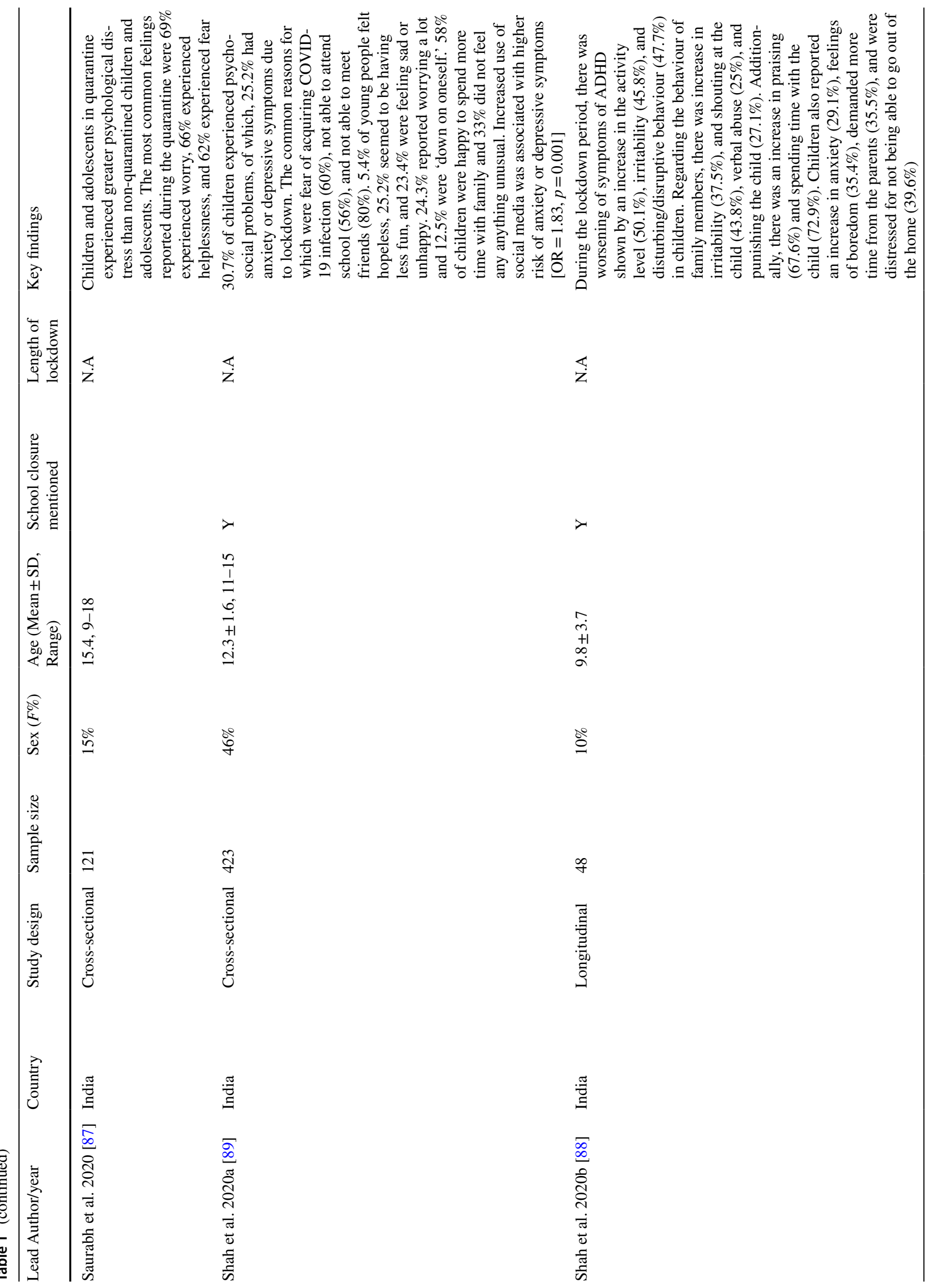




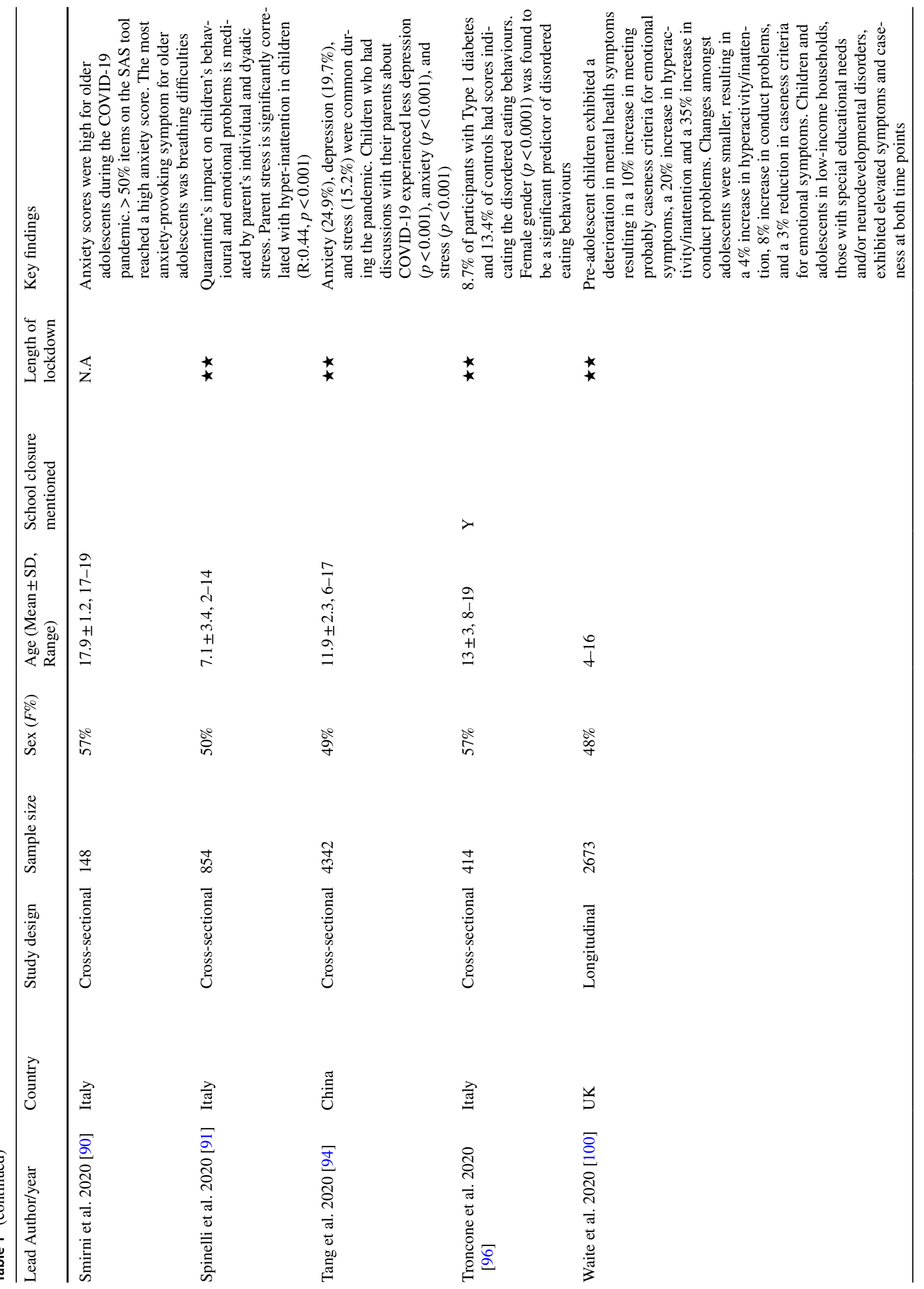




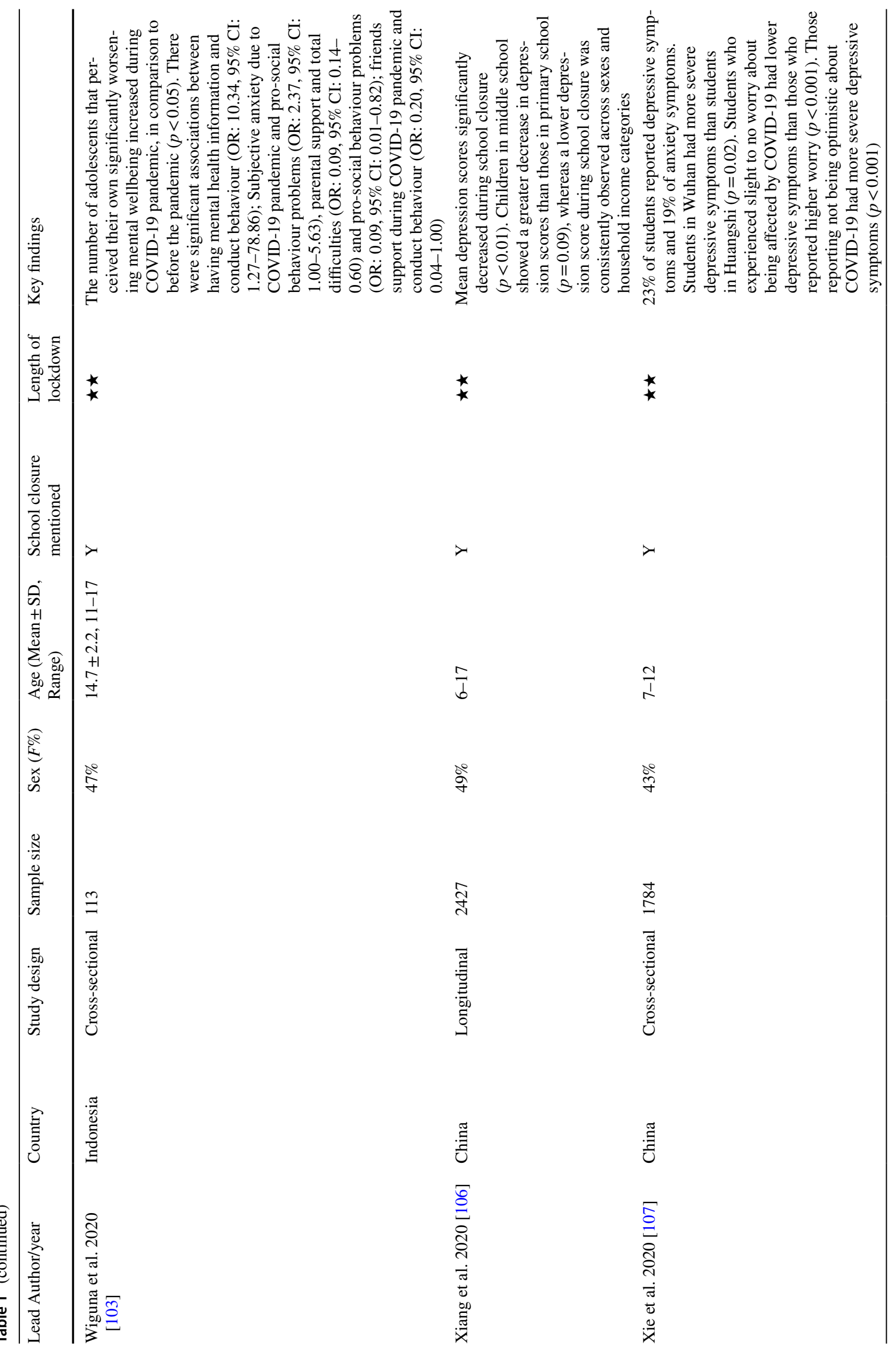




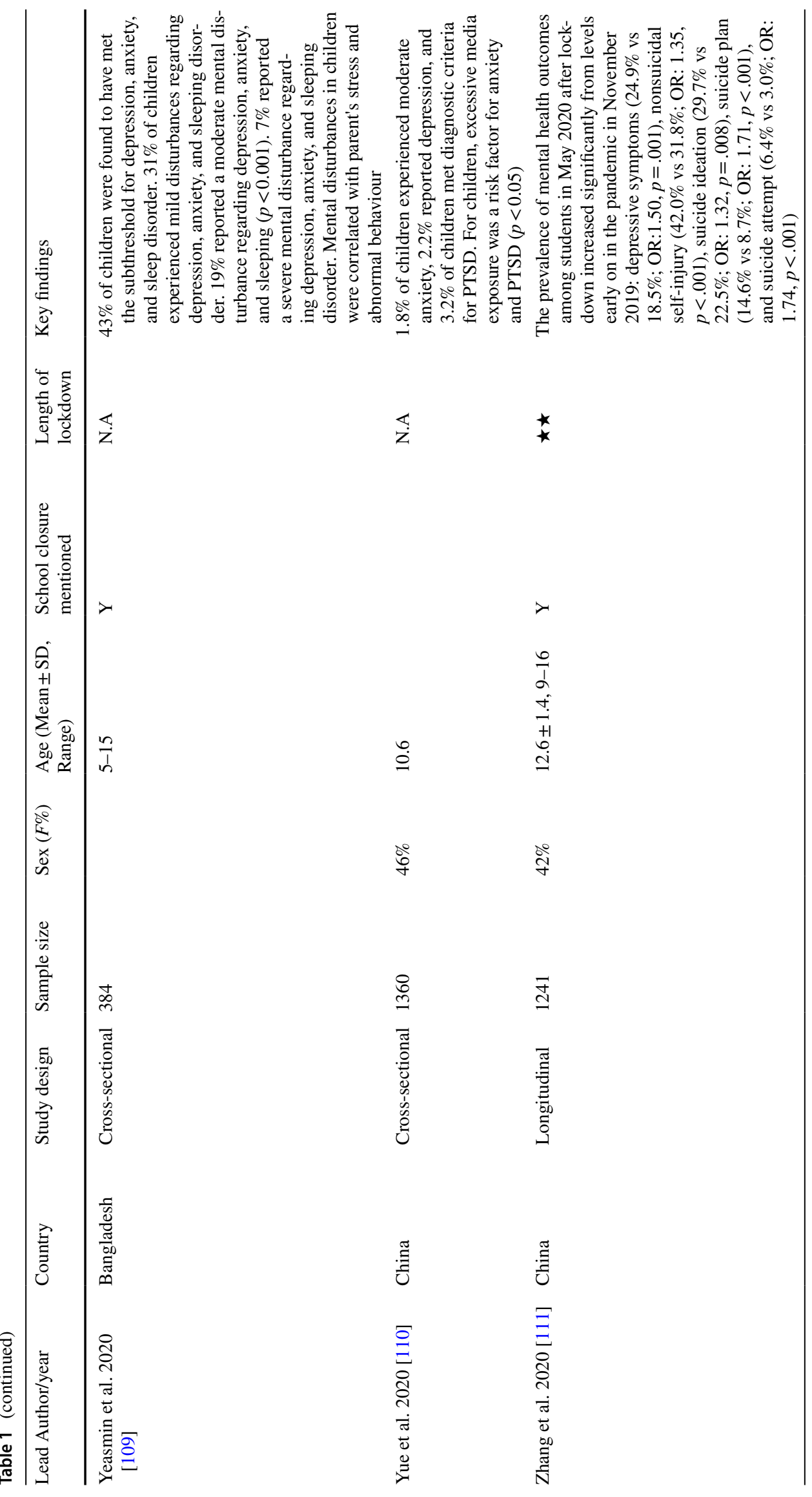




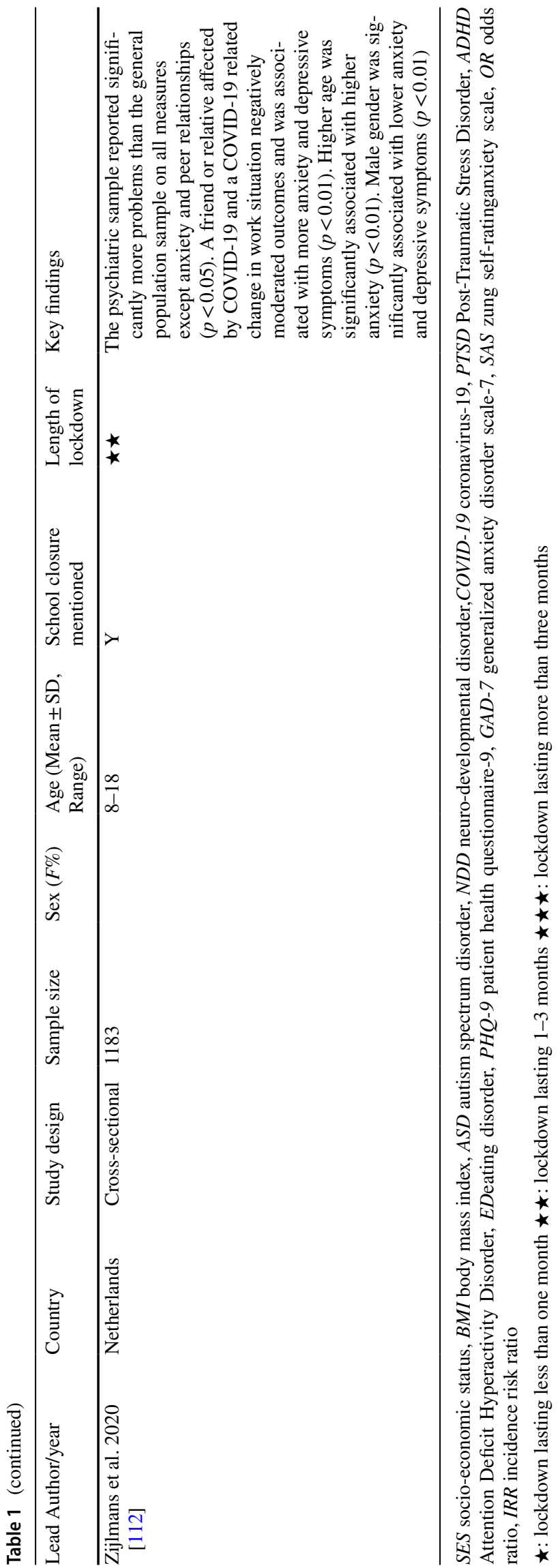

In lockdowns that lasted one month, previous service contact helped to alleviate anxiety [1]. However, longitudinal research findings showed that in a lockdown that lasted three months, children exhibited a deterioration in mental health symptoms, as reported by their parents, with a $10 \%$ increase in emotional symptoms, a $20 \%$ increase in hyperactivity/ inattention, and a 35\% increase in conduct problems [100]. Children and adolescents with special educational needs and neurodevelopmental disorders (NDD) showed more emotional symptoms, conduct problems, and hyperactivity/inattention scores than those without special educational needs and neurodevelopmental disorders [100]. Young people with NDD (28\%), specifically ADHD, showed more conduct problems through lockdown, in comparison to neurotypicals controls $(9 \%, p<0.01)$ [74]. A decrease in therapy and rehabilitation support predicted externalising behaviours in children with NDDs [11].

\section{Good mental health and protective factors}

$31.4 \%$ of children, especially 9 -year-olds (16.8\%), were seen to be calmer during the pandemic than before it, and most children were able to cope and adapt to the lockdown measures (92.6\%) [79]. Family relationships improved in $41.6 \%$ of households during lockdown [44]. Some children felt safe, relaxed, and happy when with their families $[47,48]$. Healthy parent-child relationships were associated with positive parent-child communication [94]. Parents praised their children 67.6\% more and spent $72.9 \%$ more time with them during the lockdown [88]; $58 \%$ of children were happy to spend more time with their families [89].

Some studies identified protective factors for mental health difficulties during the COVID-19 lockdown. Routines were associated with fewer symptoms of depression and improved mental health conditions in adolescents $(p<0.01)$ [38, 83]. Parent-child discussion was seen to mediate some anxiety $(\mathrm{OR}=-1.6, p<0.001)$ and depression $(\mathrm{OR}=-1.9, p<0.001)$ symptoms [94]. Parent-child discussion frequency was positively correlated to current life satisfaction $(p<0.05)$ [94]. A further protective factor for the mental health of children was play [47] (Fig. 2). Physical activity in children was associated with a lower hyperactivity-inattention risk $(\mathrm{OR}=0.44$, for $1-2$ days activity a week; $\mathrm{OR}=0.56$, for $<2$ days of activity a week) [59].

\section{Quality appraisal}

The quality appraisal of the 61 studies is summarised in eTable 5. The overall average stars achieved through the 61 included studies was 7.0 stars (range $=4-9$ ), which is considered as moderate quality. The domain of selection scored an 


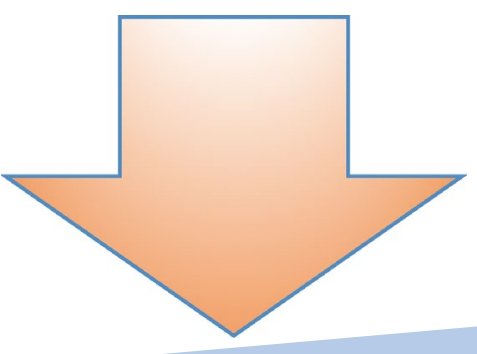

RISK FACTORS

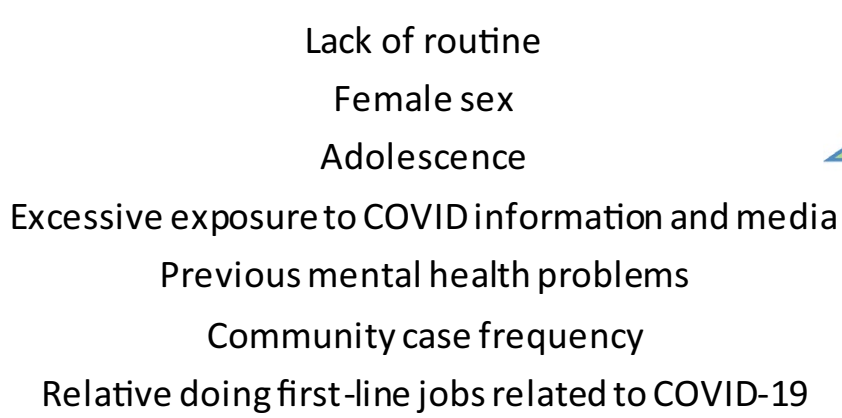

Lack of routine

Female sex

Adolescence

xcessive exposure to COVID information and media

Previous mental health problems

Community case frequency

Relative doing first-line jobs related to COVID-19

\section{PROTECTIVE FACTORS}

All types of routine

Family communication

Social support

Appropriate play and leisure
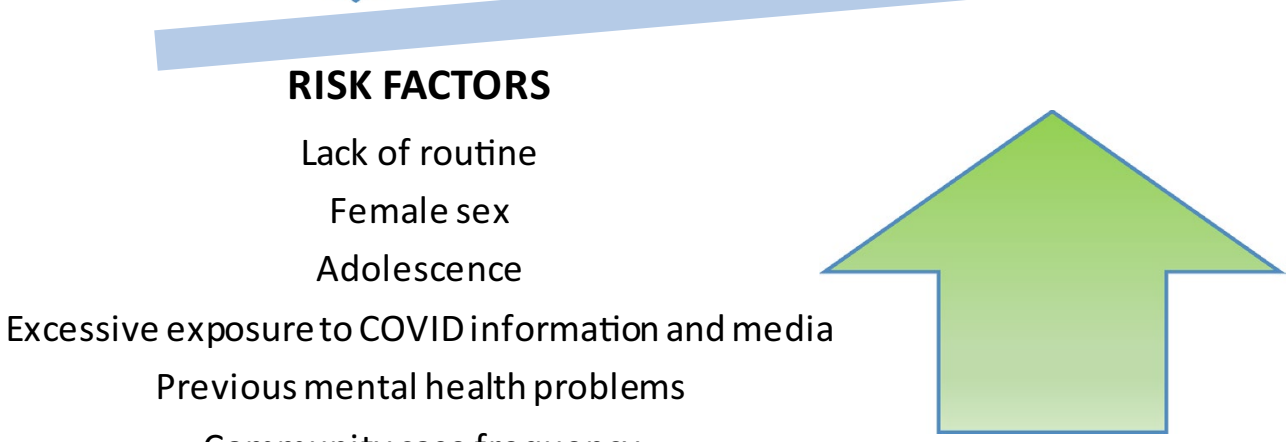

Fig. 2 Risk and protective factors for anxiety symptoms/ affective symptoms in children and adolescents. This diagram refers to the risk and protective factors that are mentioned more than once within included studies

average of 4.2/5.0 stars. The domain of comparability scored an average of $0.5 / 2.0$ stars. The domain of outcome scored an average of 2.3/3.0 stars.

\section{Discussion}

To our knowledge, this is the first systematic review to evaluate the effect of the COVID-19 lockdown on the mental health of children and adolescents. We found anxiety and depression to be the most common outcomes. A significant, substantial increase in depression and anxiety symptoms was seen in children during the lockdown compared to rates observed before the lockdown [12, 19, 62]. Other outcomes that seem to be associated with the COVID-19 lockdown are loneliness, psychological distress, anger, irritability, boredom, fear, and stress. Our results expand previous knowledge by identifying groups that may be at risk for mental health deterioration $[6,18,20,44,48,51,62,74,83,90$, $100,112]$. During the lockdown, new psychiatric conditions may appear, while children and adolescents with previous mental health conditions, such as eating disorders, may experience a reactivation $[44,51]$.

The prevalence of PTSD seen in children exposed to COVID-19 was 3.2\% [110]. This prevalence is lower than the one previously found in children quarantined or isolated due to the influenza A (H1N1) pandemic [92]. However,
PTSD symptoms usually appear months after the traumatic experience, so it may be too early to estimate its scope at the moment. Furthermore, mental health in epidemics was more impaired in the phase following the acute outbreak, than in the initial phase [22]. Future research should evaluate a potential increase in PTSD symptoms and establish appropriate measures accordingly. Specifically, preventive measures in individuals at risk are recommended to avoid reaching these dramatically high rates observed in other health-related disasters. Teacher-based, resilience-focused interventions post-trauma have shown promising results [105]. Furthermore, meta-analytical evidence suggests trauma-focused psychotherapy might be effective for the prevention of PTSD in patients with acute stress symptoms [93].

Individuals with previous eating disorders have been among the most intensively affected. $41 \%$ of young people under clinical care experienced a reactivation in eating disorder symptoms post lockdown [44], particularly those with low self-directedness and less adaptive coping strategies [9]. Lack of weight monitoring during confinement may have played a role here [9]. Individuals suffering from eating disorders struggled to maintain feeding routines and research shows COVID-19 lockdown to significantly correlate with symptoms of disordered eating [61]. Considering eating disorders have the highest mortality rate [102], there should be an increased utilisation of digital tools 
to support those with eating disorders in the context of COVID-19 [28].

This review found sociodemographic characteristics influencing the development of poor mental health outcomes associated with COVID-19 lockdown to include older age $(13-15$ vs. $6-12, p<0.03[18,83])$ and female sex $[18,20$, $62,90]$. Adolescents have been previously identified as a vulnerable group, going through an important period in their development [15] where peer relationships are of the most importance. Older adolescents displayed more depressive symptoms than younger adolescents during the lockdown [18]. This may be because the onset of depression increases as children transition into adolescence [68]. A further explanation is that adolescents are in particular need of social contact and interpersonal relationships. The period of adolescence is a motivator for peer connection [36] and the desire for peer and social support [37], which aids the development of identity [67]. However, during the lockdown, they need to attend online learning, cope with school closures and adapt to a mandatory decrease in social relations [60].

Another vulnerable group identified by this systematic review are the children and adolescents and with previous mental health difficulties or with "special educational needs and disabilities" (SEND) and/or neurodevelopmental disorders $[6,44,51,100]$. One of the reasons children and adolescents with neurodevelopmental disorders are highly vulnerable to suffering psychological distress is that while they usually prefer routine and predictable environments, the COVID-19 pandemic is a situation of fast-paced changes [24]. Children and adolescents with SEND, ASD and/or disabilities have had their carefully constructed routines suddenly disrupted [98] alongside affected support networks resulting in a higher risk of experiencing poor mental health and increased stress during the unprecedented lockdown [8]. With special education closed, these young people may struggle more with adapting to virtual schooling. Social factors in these children and adolescents are also important. $24 \%$ of teachers claimed families of those with SEND and/or disabilities don't have access to sufficiently powerful devices or software required to download or access digital materials required [77], which further complicates their situation. As a result of lockdown, symptoms of ADHD were seen to worsen $[25,34,42,59,75,85,88,100]$. Certain home environments (e.g., having a garden or adequate space at home) had a positive impact on ADHD symptoms. However, limited academic adjustments for children with ADHD were reported by parents, resulting in difficulties to carry out school-related tasks [13].

Identifying risk and protective factors is crucial for clinical practice to identify individuals who are more vulnerable to poor mental health outcomes and to develop clinical practices and public health strategies to reduce the negative impact of lockdown on children and adolescents. Risk factors include lack of routine [83], the form of internet usage [19], COVID-19 media exposure, and a relative doing first-line job responsibilities related to COVID-19 [20]. Quarantine affects the structure of children and adolescents days' [46]. Therefore, schools play an important role over lockdown as they're able to provide structure into young peoples' days which is seen to be protective, as long as they don't overburden young people [101].

In addition, school closure has been identified as a key stressor for some young people [7]. Significant associations have been found between emotional reactions and homeschool experiences [53]. 56\% of those experiencing psychosocial problems as a result of lockdown reported that this was related to not being able to attend school [89]. Furthermore, during school closure, child protection referrals from schools have decreased compared to previous years [99]. A decrease in help-seeking behaviour and access to care may have contributed negatively to the mental health of children and adolescents. The impact of school closure has not been equal for all. Children in the primary school reported fewer depressive symptoms compared to children in middle school [106].

Internet usage reduces the time being spent doing other beneficial activities and may adversely affect children's emotional health and psychological wellbeing [66]. Problematic internet usage was seen to result in psychological distress characterised by excessive time spent gaming, on one's smartphone, and on social media [19]. This has been supported by research finding that problematic internet use is associated with depression, anxiety, and other health problems [35]. Excessive time spent on the internet may occur as children are bored at home, isolated from peers, and cannot attend regular extracurricular activities. Research has found those in social isolation to have a higher level of media contact, with more exposure to COVID-19 related information [58]. During pandemics and epidemics, media exposure is reported to worsen severe mental health outcomes [21]. For instance, excessive COVID-19 media exposure has been associated with an increase in anxiety levels and stress [40]. It would be recommendable for parents to limit the time children and adolescents spend using the internet and to model positive coping behaviours [97] to reduce stress, encouraging children to carry out other activities, for example, listening to music [43], reading together, and playing board games together [55]. Physical activity also reduced hyperactivityinattention risk in children [59], which could be encouraged or recommended by caregivers. Parents and health professionals should also make sure children and adolescents get only truthful and balanced information. These aspects are a real challenge for parents that need to work remotely and simultaneously take care of their children.

Previous research has shown that family environment, parental practices, and methods of coping affect children's 
post-disaster mental health [23]. However, the lockdown has not negatively impacted everyone and may have been beneficial for some relationships to develop. Parent-child discussion was seen to be protective against child mental health, specifically anxiety, depression and stress, and is related to life satisfaction [94]. Perceived family relationship improvements may be a consequence of families being able to spend more quality time with one another due to remote working [104]; however, this can result in mental strain on some parents, especially parents of children with SEND [33]. Family relationships may serve to support child adjustment when faced with adversity [26]. In addition to this, experiencing collective family major life challenges may promote positive family transformations [65].

Numerous changes in mental health provision have occurred since the start of the COVID-19 pandemic lockdown to minimise the infection rate, such as a rise in community support services and implementing inpatient infection-control measures. To ensure continuity of mental healthcare for service users, mental health services have had to adapt mainly via adopting more telehealth methods [71, 84]. The COVID-19 lockdown has resulted in a rise in virtual, remote therapy, which may have future implications for service provision after COVID-19. For example, telehealth will allow those who live in remote areas to access mental healthcare more easily. Since COVID-19, telemedicine has been expanded, so more people are eligible for it and rules have been relaxed for health insurance providers and doctors. Telehealth reduces barriers to access, is more cost-effective, and has a wide availability of services within paediatric care [81]. However, telemedicine is limited by one's technology literacy, psychological resistance to new methods, and cultural background [52].

The findings highlighted in the present work have further clinical implications. Governments should ensure that lockdowns be as short as possible to limit the psychological effects of lockdown on children and adolescents, while protecting their safety. Governments should also aim to release COVID-19 information, information about prevention measures, and lockdown updates while ensuring that the information provided is accurate [95]. The public should have access to age-appropriate resources such as improving sleep hygiene, maintaining a balanced diet, routine keeping, and mental healthcare [101] to educate young people on keeping healthy to prevent negative psychological effects. Sleep quality $[17,25,34,39,72,79,86]$ and sleep disorders $[10$, $54,109]$ were seen to worsen during the pandemic. Therefore, easily accessible sleep hygiene resources for children may be protective against adverse sleep effects. Moreover, an increase in funding allocation to mental health services needs to be provided along with trained staff to facilitate care and ensure continuity of care for vulnerable populations and cope with the long-term mental health effects the COVID-19 lockdown may have.

Another fundamental clinical implication highlighted by this review is that the break of care due to the lockdown [45] may have delayed access to treatment, pushing the course of recovery back [84]. Clinicians should follow up on those who have experienced a break of care as they may be more vulnerable to reactivation of symptoms post lockdown. This can be done by having regular mental health check-ups for vulnerable groups to assess their mental state. Unfortunately, a reduction in self-help-seeking behaviours has been observed. For instance, hospital presentations for self-harm decreased in 2020, compared to 2019 [76] regardless of an increase in these behaviours seen during the lockdown [111]. Attention should be paid to the more vulnerable groups postlockdown when it comes to accessing mental health care and parents should also be provided psychoeducational resources to help identify psychological distress in their children [101].

We need to balance health and safety on one side and mental health and normal psychological development on the other. Short lockdowns seem to be better tolerated, especially with previous service contact [1]. However, the longer the lockdown lasts the more support children may need. For instance, children under lockdown for three months exhibited far more conduct problems [100]. Lockdowns should be made as short as possible and should assess the benefit/risk balance when deciding how long lockdowns should last to limit mental health consequences.

This study has some limitations that must be considered. First, this review does not meta-analytically evaluate the magnitude and consistency of the mental health outcomes described due to the heterogeneity of the outcomes and measurement methods. Second, evidence on the effect of lockdown on low-income households and low-income countries was limited. Further research is needed to draw conclusions on whether the impact of COVID-19 lockdown on the mental health of children and adolescents is different or not between low- and high-income countries. A third limitation is that some studies (62.3\%) did not provide details about the duration of the lockdown established, precluding drawing further conclusions from our end.

Fourth, most studies included (73.8\%) were cross-sectional, limiting causal inference. The inclusion of some cohort studies evaluating children and adolescents before and after the lockdown, allowed to evaluate more precisely the effect of lockdown while helped control some situational confounders. A fifth limitation would be that most included studies focussed on psychological reactions and symptomatology rather than the appearance of mental disorders, which has implications for practice. Future longitudinal studies should follow children and adolescents who experienced poor mental health during lockdown to see if they recover, mental health difficulties persist, or they crystalise 
into full-blown mental disorders. Lastly, most studies were conducted online, where it would be difficult for children to ask for clarification around the questions they did not understand. Due to the lockdown, children and adolescents could not attend research centres for their safety.

\section{Conclusions}

The COVID-19 lockdown has resulted in psychological distress and highlighted vulnerable groups such as those with mental health difficulties, and risk factors such as lack of routine and excessive COVID-19 media exposure. However, for some families being able to spend more quality time together has been positive. Supporting the mental health needs of children and adolescents at risk is key. Clinical guidelines to alleviate the negative effects of COVID-19 lockdown and public health strategies to support this population need to be developed.

Supplementary Information The online version contains supplementary material available at https://doi.org/10.1007/s00787-021-01856-w.

Funding Dr Salazar de Pablo is supported by the Alicia Koplowitz Foundation. Dr Moreno, Dr Parellada and Prof Arango are supported by the Spanish Ministry of Science and Innovation, Instituto de Salud Carlos III, European Regional Development Fund 'A way of making Europe', Centro de Investigación Biomédica en Red Salud Mental, Madrid Regional Government; and Fundación Mutua Madrileña.

\section{Declarations}

Conflict of interest Dr. Salazar de Pablo has received honoraria from Janssen Cilag. Dr. Moreno has been a consultant to or has received honoraria from Janssen, Angelini, Servier, Nuvelution, Otsuka, Lundbeck and Esteve outside the submitted work. Prof Arango has been a consultant to or has received honoraria or grants from Acadia, Angelini, Gedeon Richter, Janssen Cilag, Lundbeck, Otsuka, Roche, Sage, Servier, Shire, Schering Plough, Sumitomo Dainippon Pharma, Sunovion and Takeda. Prof Fusar-Poli has received research fees from Lundbeck and honoraria from Lundbeck, Angelini, Menarini and Boehringer Ingelheim outside the current study. Dr. Parellada has been a consultant to or has received honoraria from Janssen, Exeltis, Servier and Lundbeck.

Open Access This article is licensed under a Creative Commons Attribution 4.0 International License, which permits use, sharing, adaptation, distribution and reproduction in any medium or format, as long as you give appropriate credit to the original author(s) and the source, provide a link to the Creative Commons licence, and indicate if changes were made. The images or other third party material in this article are included in the article's Creative Commons licence, unless indicated otherwise in a credit line to the material. If material is not included in the article's Creative Commons licence and your intended use is not permitted by statutory regulation or exceeds the permitted use, you will need to obtain permission directly from the copyright holder. To view a copy of this licence, visit http://creativecommons.org/licenses/by/4.0/.

\section{References}

1. Abawi O, Welling MS, van den Eynde E, van Rossum EFC, Halberstadt J, van den Akker ELT, van der Voorn B (2020) COVID19 related anxiety in children and adolescents with severe obesity: a mixed-methods study. Clin Obes 10:e12412

2. Abdulah DM, Abdulla BMO, Liamputtong P (2020) Psychological response of children to home confinement during COVID-19: a qualitative arts-based research. Int J Soc Psychiatry:20764020972439

3. Achterberg M, Dobbelaar S, Boer OD, Crone EA (2021) Perceived stress as mediator for longitudinal effects of the COVID19 lockdown on wellbeing of parents and children. Sci Rep 11:2971

4. Adıbelli D, Sümen A (2020) The effect of the coronavirus (COVID-19) pandemic on health-related quality of life in children. Child Youth Serv Rev 119:105595

5. Alves JM, Yunker AG, DeFendis A, Xiang AH, Page KA (2020) Prenatal exposure to gestational diabetes is associated with anxiety and physical inactivity in children during COVID-19. Clin Obes

6. Amorim R, Catarino S, Miragaia P, Ferreras C, Viana V, Guardiano $M(2020)$ The impact of COVID-19 on children with autism spectrum disorder. Rev Neurol 71:285-291

7. Asanov I, Flores F, McKenzie D, Mensmann M, Schulte M (2021) Remote-learning, time-use, and mental health of Ecuadorian high-school students during the COVID-19 quarantine. World Dev 138:105225

8. Asbury K, Fox L, Deniz E, Code A, Toseeb U (2020) How is COVID-19 affecting the mental health of children with special educational needs and disabilities and their families? J Autism Dev Disord 1-9

9. Baenas I, Caravaca-Sanz E, Granero R, Sánchez I, Riesco N, Testa G, Vintró-Alcaraz C, Treasure J, Jiménez-Murcia S, Fernández-Aranda F (2020) COVID-19 and eating disorders during confinement: analysis of factors associated with resilience and aggravation of symptoms. Eur Eat Disord Rev 28:855-863

10. Baptista AS, Prado IM, Perazzo MF, Pinho T, Paiva SM, Pordeus IA, Serra-Negra JM (2021) Can children's oral hygiene and sleep routines be compromised during the COVID-19 pandemic? Int J Pediatr Dent 31:12-19

11. Bentenuto A, Mazzoni N, Giannotti M, Venuti P, de Falco S (2020) Psychological impact of Covid-19 pandemic in Italian families of children with neurodevelopmental disorders. Res Dev Disabil 109:103840-103840

12. Bignardi G, Dalmaijer ES, Anwyl-Irvine AL, Smith TA, Siugzdaite R, Uh S, Astle DE (2020) Longitudinal increases in childhood depression symptoms during the COVID-19 lockdown. Arch Dis Child

13. Bobo E, Lin L, Acquaviva E, Caci H, Franc N, Gamon L, Picot M, Pupier F, Speranza M, Falissard B (2020) How do children and adolescents with Attention Deficit Hyperactivity Disorder (ADHD) experience lockdown during the COVID-19 outbreak? Encephale S85-S92

14. Brooks SK, Webster RK, Smith LE, Woodland L, Wessely S, Greenberg N, Rubin GJ (2020) The psychological impact of quarantine and how to reduce it: rapid review of the evidence. Lancet 395:912-920

15. Catty J (2020) Lockdown and adolescent mental health: reflections from a child and adolescent psychotherapist. Wellcome Open Res 5

16. Cauberghe V, Van Wesenbeeck I, De Jans S, Hudders L, Ponnet K (2020) How Adolescents Use Social Media to Cope with Feelings of Loneliness and Anxiety During COVID-19 Lockdown. Cyberpsychol Behav Soc Netw 
17. Çetin FH, Uçar HN, Türkoğlu S, Kahraman EM, Kuz M, Güleç A (2020) Chronotypes and trauma reactions in children with ADHD in home confinement of COVID-19: full mediation effect of sleep problems. Chronobiol Int 37:1214-1222

18. Chen F, Zheng D, Liu J, Gong Y, Guan Z, Lou D (2020) Depression and anxiety among adolescents during COVID-19: a crosssectional study. Brain Behav Immun 88:36-38

19. Chen IH, Chen CY, Pakpour AH, Griffiths MD, Lin CY (2020) Internet-related behaviors and psychological distress among school children during COVID-19 school suspension. J Am Acad Child Adolesc Psychiatry 59:1099-1102.e1091

20. Chen S, Cheng Z, Wu J (2020) Risk factors for adolescents' mental health during the COVID-19 pandemic: a comparison between Wuhan and other urban areas in China. Global Health $16: 96$

21. Cheung Y, Chau PH, Yip PS (2008) A revisit on older adults suicides and Severe Acute Respiratory Syndrome (SARS) epidemic in Hong Kong. Int J Geriatric Psychiatry J Psychiatry Late Life Allied Sci 23:1231-1238

22. Chong M-Y, Wang W-C, Hsieh W-C, Lee C-Y, Chiu N-M, Yeh W-C, Huang T-L, Wen J-K, Chen C-L (2004) Psychological impact of severe acute respiratory syndrome on health workers in a tertiary hospital. Br J Psychiatry 185:127-133

23. Cobham VE, McDermott B, Haslam D, Sanders MR (2016) The role of parents, parenting and the family environment in children's post-disaster mental health. Curr Psychiatry Rep 18:53

24. Colizzi M, Sironi E, Antonini F, Ciceri ML, Bovo C, Zoccante L (2020) Psychosocial and behavioral impact of COVID-19 in autism spectrum disorder: an online parent survey. Brain Sci 10:341

25. Commodari E, La Rosa VL (2020) Adolescents in quarantine during COVID-19 pandemic in Italy: perceived health risk, beliefs, psychological experiences and expectations for the future. Front Psychol 11

26. Conger RD, Conger KJ (2002) Resilience in Midwestern families: Selected findings from the first decade of a prospective, longitudinal study. J Marriage Fam 64:361-373

27. Conti E, Sgandurra G, De Nicola G, Biagioni T, Boldrini S, Bonaventura E, Buchignani B, Della Vecchia S, Falcone F, Fedi C, Gazzillo M, Marinella G, Mazzullo C, Micomonaco J, Pantalone G, Salvati A, Sesso G, Simonelli V, Tolomei G, Troiano I, Cioni G, Masi G, Muratori F, Milone A, Battini R (2020) Behavioural and emotional changes during COVID-19 lockdown in an italian paediatric population with neurologic and psychiatric disorders. Brain Sci 10

28. Cooper M, Reilly EE, Siegel JA, Coniglio K, Sadeh-Sharvit S, Pisetsky EM, Anderson LM (2020) Eating disorders during the COVID-19 pandemic and quarantine: an overview of risks and recommendations for treatment and early intervention. Eat Disord $1-23$

29. Cucinotta D, Vanelli M (2020) WHO declares COVID-19 a pandemic. Acta Biomed 91:157-160

30. Cusinato M, Iannattone S, Spoto A, Poli M, Moretti C, Gatta M, Miscioscia M (2020) Stress, Resilience, and Well-Being in Italian Children and Their Parents during the COVID-19 Pandemic. Int J Environ Res Public Health 17

31. de Pablo GS, Serrano JV, Catalan A, Arango C, Moreno C, Ferre F, Shin JI, Sullivan S, Brondino N, Solmi M (2020) Impact of coronavirus syndromes on physical and mental health of health care workers: systematic review and meta-analysis. J Affect Disord

32. Deighton J, Lereya ST, Casey P, Patalay P, Humphrey N, Wolpert M (2019) Prevalence of mental health problems in schools: poverty and other risk factors among 28000 adolescents in England. Br J Psychiatry 215:565-567
33. Dhiman S, Sahu PK, Reed WR, Ganesh GS, Goyal RK, Jain S (2020) Impact of COVID-19 outbreak on mental health and perceived strain among caregivers tending children with special needs. Res Dev Disabil 107:103790

34. Di Giorgio E, Di Riso D, Mioni G, Cellini N (2020) The interplay between mothers' and children behavioral and psychological factors during COVID-19: an Italian study. Eur Child Adolesc Psychiatry

35. El Asam A, Samara M, Terry P (2019) Problematic internet use and mental health among British children and adolescents. Addict Behav 90:428-436

36. Ellis WE, Dumas TM, Forbes LM (2020) Physically isolated but socially connected: psychological adjustment and stress among adolescents during the initial COVID-19 crisis. Can J Behav Sci 52:177

37. Ellis WE, Zarbatany L (2017) Understanding processes of peer clique influence in late childhood and early adolescence. Child Dev Perspect 11:227-232

38. Ezpeleta L, Navarro JB, de la Osa N, Trepat E, Penelo E (2020) Life Conditions during COVID-19 Lockdown and Mental Health in Spanish Adolescents. Int J Environ Res Public Health 17

39. Francisco R, Pedro M, Delvecchio E, Espada JP, Morales A, Mazzeschi C, Orgilés M (2020) Psychological symptoms and behavioral changes in children and adolescents during the early phase of COVID-19 quarantine in three European Countries. Front Psychiatry 11:570164

40. Gao J, Zheng P, Jia Y, Chen H, Mao Y, Chen S, Wang Y, Fu H, Dai J (2020) Mental health problems and social media exposure during COVID-19 outbreak. PLoS ONE 15:0231924

41. Giannopoulou I, Efstathiou V, Triantafyllou G, Korkoliakou P, Douzenis A (2021) Adding stress to the stressed: senior high school students' mental health amidst the COVID-19 nationwide lockdown in Greece. Psychiatry Res 295:113560-113560

42. Gimenez-Dasi M, Quintanilla L, Lucas-Molina B, SarmentoHenrique R (2020) Six weeks of confinement: psychological effects on a sample of children in early childhood and primary education. Front Psychol 11

43. Goldbeck L, Ellerkamp T (2012) A randomized controlled trial of multimodal music therapy for children with anxiety disorders. J Music Ther 49:395-413

44. Graell M, Morón-Nozaleda MG, Camarneiro R, Villaseñor Á, Yáñez S, Muñoz R, Martínez-Núñez B, Miguélez-Fernández C, Muñoz M, Faya M (2020) Children and adolescents with eating disorders during COVID-19 confinement: difficulties and future challenges. Eur Eat Disord Rev 28:864-870

45. Guessoum SB, Lachal J, Radjack R, Carretier E, Minassian S, Benoit L, Moro MR (2020) Adolescent psychiatric disorders during the COVID-19 pandemic and lockdown. Psychiatry Res 291:113264

46. Guichard K, Geoffroy PA, Taillard J, Micoulaud-Franchi J-A, Royant-Parola S, Poirot I, Brion A, d'Ortho M-P, Gagnadoux F, Schroder C (2020) Stratégies de gestion de l'impact du confinement sur le sommeil: une synthèse d'experts. Médecine Du Sommeil 17:108-112

47. Idoiaga Mondragon N, Berasategi Sancho N, Dosil Santamaria M, Eiguren Munitis A (2021) Struggling to breathe: a qualitative study of children's wellbeing during lockdown in Spain. Psychol Health 36:179-194

48. Idoiaga N, Berasategi N, Eiguren A, Picaza M (2020) Exploring children's social and emotional representations of the COVID-19 pandemic. Front Psychol 11:1952

49. Imran N, Aamer I, Sharif MI, Bodla ZH, Naveed S (2020) Psychological burden of quarantine in children and adolescents: a rapid systematic review and proposed solutions. Pak J Med Sci 36:1106-1116 
50. Jiloha R (2020) COVID-19 and mental health. Epidemiology International (E-ISSN: 2455-7048) 5:7-9

51. Kılınçel Ş, Kılınçel O, Muratdağı G, Aydın A, Usta MB (2020) Factors affecting the anxiety levels of adolescents in home-quarantine during COVID-19 pandemic in Turkey. Asia Pac Psychiatry e 12406

52. Kinoshita S, Cortright K, Crawford A, Mizuno Y, Yoshida K, Hilty D, Guinart D, Torous J, Correll CU, Castle DJ (2020) Changes in telepsychiatry regulations during the COVID-19 pandemic: 17 countries and regions' approaches to an evolving healthcare landscape. Psychol Med 1-8

53. Larsen L, Helland MS, Holt T (2020) The Impact of School Closure and Social Isolation on Children in Vulnerable Families during COVID-19: A Focus on Children's Reactions.

54. Lecuelle F, Leslie W, Huguelet S, Franco P, Putois B (2020) Did the COVID-19 lockdown really have no impact on young children's sleep? J Clin Sleep Med 16:2121-2121

55. Li WH, Chung JOK, Ho KY, Kwok BMC (2016) Play interventions to reduce anxiety and negative emotions in hospitalized children. BMC Pediatr 16:1-9

56. Liang Z, Delvecchio E, Buratta L, Mazzeschi C (2020) "Ripple effect": Psychological responses and coping strategies of Italian children in different COVID-19 severity areas. Revista De Psicologia Clinica Con Ninos Y Adolescentes 7:49-58

57. Liébana-Presa $\mathrm{C}$, Martínez-Fernández MC, Benítez-Andrades JA, Fernández-Martínez E, Marqués-Sánchez P, García-Rodríguez I (2020) Stress, emotional intelligence and the intention to use cannabis in Spanish adolescents: influence of COVID-19 confinement. Front Psychol 11:582578

58. Liu C, Liu Y (2020) Media exposure and anxiety during COVID19: the mediation effect of media vicarious traumatization. Int $\mathbf{J}$ Environ Res Public Health 17:4720

59. Liu Q, Zhou Y, Xie X, Xue Q, Zhu K, Wan Z, Wu H, Zhang J, Song R (2021) The prevalence of behavioral problems among school-aged children in home quarantine during the COVID-19 pandemic in china. J Affect Disord 279:412-416

60. Liu Y, Yue S, Hu X, Zhu J, Wu Z, Wang J, Wu Y (2021) Associations between feelings/behaviors during COVID-19 pandemic lockdown and depression/anxiety after lockdown in a sample of Chinese children and adolescents. J Affect Disord

61. Machado PP, Pinto-Bastos A, Ramos R, Rodrigues TF, Louro E, Gonçalves S, Brandão I, Vaz A (2020) Impact of COVID-19 lockdown measures on a cohort of eating disorders patients. J Eat Disord 8:1-8

62. Magson NR, Freeman JYA, Rapee RM, Richardson CE, Oar EL, Fardouly J (2021) Risk and protective factors for prospective changes in adolescent mental health during the COVID-19 pandemic. J Youth Adolesc 50:44-57

63. Majeed S, Ashraf M (2020) Psychological impacts of social distancing during COVID-19 pandemic in adolescents of Lahore, Pakistan. Ann King Edward Med Univ Lahore Pak 26:165-169

64. Mallik CI, Radwan RB (2021) Impact of lockdown due to COVID-19 pandemic in changes of prevalence of predictive psychiatric disorders among children and adolescents in Bangladesh. Asian J Psychiatr 56:102554

65. Masten AS, Narayan AJ (2012) Child development in the context of disaster, war, and terrorism: pathways of risk and resilience. Annu Rev Psychol 63:227-257

66. McDool E, Powell P, Roberts J, Taylor K (2020) The internet and children's psychological wellbeing. J Health Econ 69:102274

67. Meeus W, Dekovic M (1995) Identity development, parental and peer support in adolescence: results of a national Dutch survey. Adolescence 30:931-945

68. Merikangas KR, He J-p, Burstein M, Swanson SA, Avenevoli S, Cui L, Benjet C, Georgiades K, Swendsen J (2010) Lifetime prevalence of mental disorders in US adolescents: results from the National Comorbidity Survey Replication-Adolescent Supplement (NCS-A). J Am Acad Child Adolesc Psychiatry 49:980-989

69. Modesti PA, Reboldi G, Cappuccio FP, Agyemang C, Remuzzi G, Rapi S, Perruolo E, Parati G, Settings EWGoCRiLR (2016) Panethnic differences in blood pressure in Europe: a systematic review and meta-analysis. PLoS ONE 11:e0147601

70. Moher D, Liberati A, Tetzlaff J, Altman DG, Group P (2009) Preferred reporting items for systematic reviews and metaanalyses: the PRISMA statement. BMJ 339:2535

71. Moreno C, Wykes T, Galderisi S, Nordentoft M, Crossley N, Jones N, Cannon M, Correll CU, Byrne L, Carr S, Chen EYH, Gorwood P, Johnson S, Kärkkäinen H, Krystal JH, Lee J, Lieberman J, López-Jaramillo C, Männikkö M, Phillips MR, Uchida H, Vieta E, Vita A, Arango C (2020) How mental health care should change as a consequence of the COVID-19 pandemic. Lancet Psychiatry 7:813-824

72. Morgul E, Kallitsoglou A, Essau CA (2020) Psychological effects of the COVID-19 lockdown on children and families in the UK. Revista De Psicologia Clinica Con Ninos Y Adolescentes 7:42-48

73. Mourouvaye M, Bottemanne H, Bonny G, Fourcade L, Angoulvant F, Cohen JF, Ouss L (2020) Association between suicide behaviours in children and adolescents and the COVID-19 lockdown in Paris, France: a retrospective observational study. Arch Dis Child

74. Nonweiler J, Rattray F, Baulcomb J, Happe F, Absoud M (2020) Prevalence and Associated Factors of Emotional and Behavioural Difficulties during COVID-19 Pandemic in Children with Neurodevelopmental Disorders. Children-Basel 7

75. Orgilés M, Morales A, Delvecchio E, Mazzeschi C, Espada JP (2020) Immediate psychological effects of the COVID-19 quarantine in youth from Italy and Spain. Front Psychol 11:579038

76. Ougrin D, Wong HC, Vaezinejad M, Plener PL, Mehdi T, Romaniuk L, Barrett E, Hussain H, Lloyd A, Tolmac J (2020) Pandemic-Related Emergency Psychiatric Presentations for Self-Harm of Children and Adolescents in 10 Countries (PREP-Kids): A Retrospective International Cohort Study.

77. Parmigiani D, Benigno V, Giusto M, Silvaggio C, Sperandio S (2020) E-inclusion: online special education in Italy during the Covid-19 pandemic. Technol Pedagog Educ 1-14

78. Patra S, Patro BK, Acharya SP (2020) COVID-19 lockdown and school closure: Boon or bane for child mental health, results of a telephonic parent survey. Asian J Psychiatr 54:102395

79. Pisano L, Galimi D, Cerniglia L (2020) A qualitative report on exploratory data on the possible emotional/behavioral correlates of Covid-19 lockdown in 4-10 years children in Italy

80. Pons J, Ramis Y, Alcaraz S, Jordana A, Borrueco M, Torregrossa M (2020) Where did all the sport go? negative impact of COVID19 lockdown on life-spheres and mental health of spanish young athletes. Front Psychol 11

81. Racine N, Hartwick C, Collin-Vézina D, Madigan S (2020) Telemental health for child trauma treatment during and postCOVID-19: limitations and considerations. Child Abuse Neglect 110:104698

82. Radwan E, Radwan A, Radwan W (2020) The role of social media in spreading panic among primary and secondary school students during the COVID-19 pandemic: an online questionnaire study from the Gaza Strip, Palestine. Heliyon 6:e05807-e05807

83. Ren H, He X, Bian X, Shang X, Liu J (2021) The protective roles of exercise and maintenance of daily living routines for Chinese adolescents during the COVID-19 quarantine period. J Adolesc Health 68:35-42 
84. Revet A, Hebebrand J, Anagnostopoulos D, Kehoe LA, Klauser $P$ (2021) ESCAP CovCAP survey of heads of academic departments to assess the perceived initial (April/May 2020) impact of the COVID-19 pandemic on child and adolescent psychiatry services. Eur Child Adolesc Psychiatry 1-10

85. Romero E, López-Romero L, Domínguez-Álvarez B, Villar P, Gómez-Fraguela JA (2020) Testing the effects of COVID-19 confinement in Spanish Children: the role of parents' distress, emotional problems and specific parenting. Int J Environ Res Public Health 17

86. Sama BK, Kaur P, Thind PS, Verma MK, Kaur M, Singh DD (2021) Implications of COVID-19-induced nationwide lockdown on children's behaviour in Punjab, India. Child Care Health Dev 47:128-135

87. Saurabh K, Ranjan S (2020) Compliance and psychological impact of quarantine in children and adolescents due to COVID19 pandemic. Indian J Pediatr 87:532-536

88. Shah R, Raju VV, Sharma A, Grover S (2020) Impact of COVID19 and lockdown on children with ADHD and their families-an online survey and a continuity care model. J Neurosci Rural Pract

89. Shah S, Kaul A, Shah R, Maddipoti S (2020) Impact of Coronavirus Disease 2019 Pandemic and Lockdown on Mental Health Symptoms in Children. Indian Pediatrics

90. Smirni P, Lavanco G, Smirni D (2020) Anxiety in older adolescents at the time of COVID-19. J Clin Med 9

91. Spinelli M, Lionetti F, Pastore M, Fasolo M (2020) Parents' stress and children's psychological problems in families facing the COVID-19 outbreak in Italy. Front Psychol 11

92. Sprang G, Silman M (2013) Posttraumatic stress disorder in parents and youth after health-related disasters. Disaster Med Public Health Prep 7:105-110

93. Stockings E, Degenhardt L, Dobbins T, Lee Y, Erskine H, Whiteford H, Patton G (2016) Preventing depression and anxiety in young people: a review of the joint efficacy of universal, selective and indicated prevention. Psychol Med 46:11-26

94. Tang S, Xiang M, Cheung T, Xiang YT (2021) Mental health and its correlates among children and adolescents during COVID19 school closure: the importance of parent-child discussion. $\mathbf{J}$ Affect Disord 279:353-360

95. Tran BX, Dang AK, Thai PK, Le HT, Le XTT, Do TTT, Nguyen TH, Pham HQ, Phan HT, Vu GT (2020) Coverage of health information by different sources in communities: implication for COVID-19 epidemic response. Int J Environ Res Public Health $17: 3577$

96. Troncone A, Chianese A, Zanfardino A, Cascella C, Piscopo A, Borriello A, Rollato S, Casaburo F, Testa V, Iafusco D (2020) Disordered eating behaviors in youths with type 1 diabetes during COVID-19 lockdown: an exploratory study. J Eat Disord 8

97. Urbina-Garcia A (2020) Young Children's Mental Health: Impact of Social Isolation During The COVID-19 Lockdown and Effective Strategies

98. Vieta E, Pérez V, Arango C (2020) Psychiatry in the aftermath of COVID-19. Revista de Psiquiatria y Salud Mental 13:105-110

99. Viner RM, Russell S, Saulle R, Croker H, Stansfield C, Packer J, Nicholls D, Goddings A-L, Bonell C, Hudson L (2021) Impacts of school closures on physical and mental health of children and young people: a systematic review. MedRxiv

100. Waite P, Pearcey S, Shum A, Raw J, Patalay P, Creswell C (2020) How did the mental health of children and adolescents change during early lockdown during the COVID-19 pandemic in the UK?

101. Wang G, Zhang Y, Zhao J, Zhang J, Jiang F (2020) Mitigate the effects of home confinement on children during the COVID-19 outbreak. Lancet 395:945-947

102. Weiselberg E, Gonzalez M, Fisher M (2011) Eating disorders in the twenty-first century. Minerva Ginecol 63:531-545

103. Wiguna T, Anindyajati G, Kaligis F, Ismail RI, Minayati K, Hanafi E, Murtani BJ, Wigantara NA, Putra AA, Pradana K (2020) Brief Research Report on Adolescent Mental Well-Being and School Closures During the COVID-19 Pandemic in Indonesia. Front Psychiatry 11

104. Williams L, Rollins L, Young D, Fleming L, Grealy M, Janssen X, Kirk A, MacDonald B, Flowers P (2021) What have we learned about positive changes experienced during COVID-19 lockdown? Evidence of the social patterning of change. PLoS ONE 16:e244873

105. Wolmer L, Hamiel D, Laor N (2011) Preventing children's posttraumatic stress after disaster with teacher-based intervention: a controlled study. J Am Acad Child Adolesc Psychiatry 50:340$348((\mathbf{e 3 4 2}))$

106. Xiang M, Yamamoto S, Mizoue T (2020) Depressive symptoms in students during school closure due to COVID-19 in Shanghai. Psychiatry Clin Neurosci 74:664-666

107. Xie X, Xue Q, Zhou Y, Zhu K, Liu Q, Zhang J, Song R (2020) Mental health status among children in home confinement during the coronavirus disease 2019 outbreak in Hubei Province, China. JAMA Pediatr 174:898-900

108. Xiong J, Lipsitz O, Nasri F, Lui LMW, Gill H, Phan L, Chen-Li D, Iacobucci M, Ho R, Majeed A, McIntyre RS (2020) Impact of COVID-19 pandemic on mental health in the general population: a systematic review. J Affect Disord 277:55-64

109. Yeasmin S, Banik R, Hossain S, Hossain MN, Mahumud R, Salma N, Hossain MM (2020) Impact of COVID-19 pandemic on the mental health of children in Bangladesh: a cross-sectional study. Child Youth Serv Rev 117:105277

110. Yue J, Zang X, Le Y, An Y (2020) Anxiety, depression and PTSD among children and their parent during 2019 novel coronavirus disease (COVID-19) outbreak in China. Curr Psychol 1-8

111. Zhang L, Zhang D, Fang J, Wan Y, Tao F, Sun Y (2020) Assessment of mental health of chinese primary school students before and after school closing and opening during the COVID-19 pandemic. Jama Netw Open 3

112. Zijlmans J, Teela L, van Ewijk H, Klip H, van der Mheen M, Ruisch H, Luijten M, van Muilekom M, Oostrom K, Buitelaar J (2020) Mental and social health of children and adolescents with pre-existing mental or somatic problems during the COVID-19 pandemic lockdown. MedRxiv 